\title{
Revista

\section{EL BASTÓN ROJO SE SOSTIENE: CONOCIMIENTO CULTURAL DEL PUEBLO KAQCHIKEL}

Jorge Urdapilleta Carrasco

El Colegio de la Frontera Sur

jurdapilleta@ecosur.edu.mx

Kajkan Felipe Mejía Sepet Comunidad Lingüística Kaqchikel

kajkan_ixim@yahoo.com

\section{RESUMEN}

Se comparte un análisis de los principales elementos del conocimiento cultural del pueblo Kaqchikel. Se muestra el papel fundamental de la espiritualidad y la manera como esta orienta su vida; evidencia la dialéctica panteísta como parte constitutiva de su cosmovisión, mediante el repaso de algunos documentos históricos y de interpretaciones compartidas por guías espirituales de este pueblo.

PALABRAS CLAVE: conocimiento cultural, cosmovisión, resistencia, espiritualidad, dialéctica panteísta.

\section{THE RED STAFF OF POWER PERDURES: CULTURAL KNOWLEDGE OF THE KAQCHIKEL PEOPLE}

\section{ABSTRACT}

This paper analyzes the core elements of the cultural knowledge of the Kaqchikel people. It shows the essential role played by spirituality and how it orients life. Through reviewing some historical documents and interpretations shared by Kaqchikel spiritual guides, a pantheistic dialectic as a constitutional aspect of their cosmovision is revealed.

KEY WORDS: cultural knowledge, cosmovision, resistance, spirituality, pantheistic dialectic.

\section{KOLONÏK RI KÄQ PATÄN: RETAMAB'AL B'ANOB'ÄL RI KAQCHIKEL TINAMÏT}

\section{CH'UTIRISANEM SAMAJ}

Chupam ri jun tz'ib'anïk re' nq'alajisäx apo jun ch'ob'onïk chi rij ruk'aslemal ri Kaqchikel tinamït, rub'eyal kik'osan pe ki k'aslem, kikoch'on pe rupoqonal kik'aslemal, richin re jun rutzijol na'oj re' xtz'et kipam jalajöj ojer taq wuj, chuqa' kitzij jalajöj taq aja'ija', k'amol b'ey, k'exeloma', richin ke ri' nqak'ut apo ruk'aslemal re tinamït re', ri ek'äs wakami.

RUWÄCH TZIJ: Rutzijoxik kajulew, Tz'etkajulew, K'ula Kajulew, Nimab'äl K'u'x. 


\section{INTRODUCCIÓN}

$\mathrm{D}$ urante la época colonial la cultura de los pueblos indígenas en Guatemala fue llamada paganismo, bajo el auspicio de la Iglesia católica. ${ }^{1}$ Posteriormente fue utilizada a conveniencia por parte del Estado guatemalteco, al asumirla como un simple conjunto de tradiciones o creencias «atrasadas». En la actualidad, el acervo de saberes que entrañan estas visiones del mundo, con sus lenguas propias, aparentemente está pereciendo a causa del epistemicidio que se ha acentuado con la globalización.

En lo que respecta a la espiritualidad, si bien se han hecho varios trabajos relevantes acerca de la llamada religión Maya', estos se basaron en la interpretación que sus respectivos autores (Thompson 1979, Farris 1984) tuvieron tanto de los sitios arqueológicos más importantes —en especial Palenque, Chichén Itzá y Tikal_ como de los principales códices que se han logrado conservar, como el Dresde, París o Madrid. En el caso de trabajos recientes, como los de Freidel et al. (1999), con todo y que hubo además un mayor acercamiento a las prácticas actuales, aun así, eran interpretaciones hechas por actores externos.

Por lo tanto, buscando enriquecer la comprensión de la cultura Maya', en el presente escrito intentamos integrar la visión académica con la práctica cultural, de forma que el análisis contenga una base teórica que respalde nuestra interpretación de los sentidos de la espiritualidad Maya' actual, tomando el caso concreto del pueblo Kaqchikel, ${ }^{2}$ y contribuir a la propuesta que hay entre un grupo creciente de ajq'ija' (guías espirituales Maya) de promover una práctica cada vez más abierta de las ceremonias propias de esa cultura, tanto al interior como al exterior de las comunidades, siendo esta una muestra de cómo los pueblos de ese origen se niegan a desaparecer (Rupflin-Alvarado 1999).

A fin de no realizar un análisis en el que pueda permear la visión de la antropología colonial, asumiremos la categoría de Conocimiento Cultural según el planteamiento de Fernando Limón (2010). Con dicho término se busca sumarse a la apuesta de Epistemología del Sur de Boaventura de Sousa Santos (2009) de reconocer las formas de conocimiento que han sido declaradas como

\footnotetext{
${ }^{1}$ Véase la bula Romanus Pontifex emitida por el papa Nicolás V en 1452 y la manera en la que fray Diego de Landa (1986) explicó el origen del calendario Maya' al sugerir que lo inspiró el demonio.

2 Este nombre también lo han escrito como Cakchiqueles o Kaqchiqueles, pero respetamos la forma aceptada por la Academia de las Lenguas Mayas de Guatemala, en lo tocante a que los nombres de todos los grupos indígenas guatemaltecos deben ir con mayúscula inicial. De igual forma, procuraremos respetar otros vocablos y formas particulares de escribir en lengua Kaqchikel.
} 
inexistentes o insuficientes y que se han mantenido en resistencia. En este caso, los conocimientos culturales del pueblo Kaqchikel son una muestra fidedigna de la resistencia a subsumirse en la pretendida cultura nacional criolla, misma que ha buscado tomar a conveniencia elementos de las culturas indígenas, creando ideas y situaciones que fueran favorables para el Estado guatemalteco. Ejemplos de lo anterior son el mito fraudulento de Tekum Umam (Paz-Cárcamo 2006), o la distorsión del sentido de la espiritualidad, que ha implicado en muchos casos la comercialización del calendario Maya' o la irrupción turística en centros ceremoniales.

Para sustentar nuestras interpretaciones se hará una breve relación de sucesos históricos que nos ayuden a describir el pasado de este pueblo, el cual desde sus orígenes ha luchado por preservar su autonomía, tanto frente al pueblo K'iche', como ante los españoles y criollos. Para ello se consultaron documentos históricos y obras de autores que han abordado aspectos relacionados con nuestro tema, como Bernal Díaz del Castillo (1980), fray Bernardino de Sahagún (2006), fray Diego de Landa (1986), fray Francisco Ximénez (1985), Pedro Cortés y Larraz, Francisco Fuentes y Guzmán (1932), Daniel Brinton (2012), George Guillemin (1980), Guillermo Paz-Cárcamo (2004, 2006), Demetrio Cojtí (2006), Eric Thompson (1966, 1979), Nancy Farris (1984), Severo Martínez Peláez (1998), Antonio García de León (1985), David Freidel, Linda Schele y Joy Parker (1999).

Posteriormente se hará una descripción de la interpretación que tienen ajq'ija' de diferentes poblados kaqchikela' —Tecpán, Chimaltenango, Sololá- sobre los principales elementos del conocimiento cultural de este pueblo, los cuales fueron organizados en las siguientes categorías: el Tiempo, el Territorio, la Comunidad, el Idioma, el Fuego Sagrado, los Guardianes y los Ancestros, la Armonía o el Equilibrio en la Vida. Dado que estas categorías son compartidas por diferentes pueblos de origen Maya', también incluimos las visiones que de esta tienen ajq'ija de origen K'iche', Achí', Poqomam, Mam y Chuj.

En esta consulta destacan las ideas compartidas dentro del Consejo del Pueblo Maya' Kaqchikel, el Consejo de Juventudes Indígenas y el Consejo de Autoridades Ancestrales Maya' Kaqchikela' «Kaji'Imox - B'eleje'K'at» de Tecpán. Al respecto se debe aclarar que mucho del conocimiento que sustenta las ideas aquí expuestas fue compartido por vía oral, por ser el esquema que tradicionalmente se ha empleado, aunque existen algunos casos de documentos y publicaciones generados dentro de los diferentes consejos. 
Finalmente, si bien la resistencia del pueblo Kaqchikel ha tomado matices políticos y ha derivado en movimientos sociales, dada la extensión del artículo nos centraremos más en cuestiones de tipo espiritual, eje fundamental de la resistencia del pueblo.

\section{CONOCIMIENTO CULTURAL}

El término «cultura», abordado por autores como Javier San Martín (1999), tiene un fuerte antecedente de colonialismo y está impregnado de nociones evolucionistas — como las manejadas por Lewis Morgan (1944)_, en combinación con las ideas sobre lo que es ser «civilizado». ${ }^{3} \mathrm{~A}$ la luz de esta crítica, hay que tomar conciencia de los grilletes que siguen imponiendo los paradigmas del desarrollo y de la modernidad, con los cuales se valora a los individuos a partir del acceso a los recursos económicos y tecnológicos, con un enfoque lineal cuyo ideal es el crecimiento continuo encaminado a un consumo a gran escala, como el que planteara Rostow (1993) a mediados del siglo XX.

Es así que, teniendo como referencia central la definición del término cultura de Olivé (2004)4 _inspirado a su vez en las ideas de Kymlicka, Salmerón y Villoro-, el conocimiento cultural no solo hace alusión a todos los saberes construidos históricamente, de manera diferenciada, por los pueblos, sino que además tienen la característica de que dan sustento a modos particulares de vida. Es por ello que deben ser vistos en «un sentido de constelación particular de su existir, precisamente en relación dialéctica con su propia cultura como resistencia a los discursos organizados en el contexto» (Limón 2010:22-23). Es decir, son resultado de un movimiento que busca la afirmación de la peculiaridad al tiempo que nutre la intersubjetividad libre de sometimiento.

${ }^{3}$ El primer uso del término civilisation fue por parte del fisiócrata Mirabeau, en 1757, quien solía significar «el proceso colectivo y original que hacía que la humanidad emergiera de la barbarie», y este uso estaba incluso conduciendo para entonces hacia la definición de civilisation (Kuper 2001:45).

${ }^{4}$ «Una cultura es una comunidad que tiene una tradición desarrollada a lo largo de varias generaciones, cuyos miembros realizan cooperativamente diferentes prácticas, por ejemplo, cognitivas, educativas, religiosas, económicas, políticas, tecnológicas, lúdicas y de esparcimiento - lo cual significa estar orientados dentro de esas prácticas por creencias, normas, valores y reglas comunes-, que comparten una o varias lenguas, una historia y varias instituciones, que mantienen expectativas comunes y se proponen desarrollar colectivamente proyectos significativos para todos ellos» (Olivé 2004:31-32). 
Al usar el término de constelación —retomado de Max Weber- el autor está reconociendo el vínculo con el entramado de sucesos pasados y la forma en la cual crean significados, en el presente, desde su núcleo. Esa creación de significados proviene del modo particular de existir, siendo la principal fuerza de la historia el sentido de resistencia, puesto que las memorias y vivencias, incluidos los dolores, moldean el sueño lúcido del porvenir, concebido en oposición a la perspectiva racionalista y su consiguiente pretensión de homogeneidad.

Si bien Worsley (1974) reconoció la importancia de ese sentido del existir, en lo que denominó los aspectos emotivos de la cultura, estos carecen del punto medular del conocimiento cultural: la resistencia. El entendimiento del sentido de resistencia es fundamental para comprender la existencia de los pueblos indígenas y la de aquellos grupos que se asumen como diferentes. En el caso de los primeros, su particularidad les fue negada desde el momento en que se inventó el término «indio», pasando por una serie de descalificaciones con las que se cuestionó si tenían alma, si tenían igual capacidad intelectual que los europeos, o bien, más tarde se asentó el prejuicio de que no quieren «desarrollarse».

A fin de poder concretar los rasgos esenciales del conocimiento cultural, a continuación los exponemos en forma sintética:

Constelación de la existencia: conocimiento resultado de una construcción histórica, en la cual el vínculo con el pasado le da sentido a las acciones presentes. Para Panikkar (1999:21) el ser humano tiene memoria más allá de su historia individual, de forma que nuestro lenguaje y nuestra biología condensan la experiencia de innumerables generaciones. En el caso de los pueblos indígenas sería el reconocimiento a los ancestros y el respeto a la tradición. Dentro de esta característica también habrán de situarse la conciencia histórica en el contexto y los valores de cada pueblo, que son los que orientan las prácticas.

Particularidad: cada pueblo articula, significa y resignifica los conocimientos según la constelación particular de su existir y generalmente en relación con su territorio.

Resistencia: la constelación de la existencia se da en un sentido de resistencia frente a los discursos organizados en el contexto, y que son la vía a través de la cual se pretende imponer una visión hegemónica. La resistencia a aceptar valores impuestos es una muestra clave, y que suele pasar inadvertida.

Esperanza: el sueño lúcido que toda persona tiene y que habrá de ser una mirada serena que ayude a clarificar los rumbos, teniendo claros los anhelos. Esa esperanza toma fuerza al ser un sueño colectivo que se ajusta a las condiciones de 
cada sujeto. La esperanza se nutre de la resistencia en la forma del «todavía no» referido por Bloch (1980), el cual, al inscribirse en el presente, lo dilata, ayudando a redeterminar «activamente todo aquello que tocan. De ese modo, cuestionan las determinaciones que se presentan como constitutivas de un momento dado o condición» (Santos 2009:46).

Renovación: aunque aparentemente el conocimiento cultural sugiera un apego al pasado que limite cualquier cambio, no es así, puesto que se reconoce el carácter dinámico de la historia. En esta parte se ha de identificar el conflicto inherente al cambio, sobre todo en la transición generacional.

Tomando como guía esta propuesta de Limón (2010) y la aplicación que hizo de este término en la interpretación de la existencia del pueblo Chuj, presentaremos los elementos constitutivos del pueblo Kaqchikel, desde nuestra perspectiva, sobre la tradición que nos ha sido compartida, por lo que no pretendemos dar una definición absoluta de su cosmovisión. Además, respetando que no existe el término de religión como tal en esa lengua ni en esa cultura, habremos de apoyarnos en el Nimab'äl K'u'x que alude al 'estado de grandeza del corazón'.

Según el acuerdo del Consejo de Autoridades Ancestrales Maya' Kaqchikela' «Kaji' Imox - B'eleje' K'at», el Nimab'äl K'u'x tiene que verse como «un reencauzamiento del ser individual hacia el ser colectivo», lo cual implica entender que la dinámica de la vida no es una cuestión antropocéntrica, sino que "existen diferentes niveles en la totalidad de la vida, mismos que se expresan en la naturaleza y el universo». En general, el Nimab'äl K'u'x es «una práctica colectiva encaminada a la transformación de la persona, en sintonía con el resto de seres con quienes se comparte la existencia y en cuya interacción podemos crecer y lograr la armonía».

A la luz de esto último, hacemos notar la dificultad que puede haber para lograr una comprensión entre pueblos con una visión que reconoce la integración con todos los seres, y la antropocéntrica, simplemente porque los primeros tienen mayor disposición a reconocer la posibilidad de que otros seres no humanos se expresen y disientan, cuestión que para fines académicos proponemos llamar «dialéctica panteísta».

Partimos de tomar la propuesta de la dialéctica negativa de Adorno (2007), la cual tiene que ver con la búsqueda de ampliar el campo de lo posible mediante la aceptación del disenso como fuente de conocimiento. Es decir, a diferencia de la dialéctica de Hegel, que propone el modelo tesis-antítesis-síntesis, para Adorno no existe la síntesis como última estación que nos brinde el consenso 
definitivo. Al contrario, el disenso debe ser reconocido como una posibilidad. Para Santos (2009) y la "Sociología de las ausencias», es la escucha de las voces y culturas excluidas. En el caso de la dialéctica panteísta, el pueblo Kaqchikel reconoce además la ampliación de la posibilidad de disenso en la naturaleza.

Con el término panteísta denotamos la sustancia de aquella corriente filosófica que asume todo lo existente como parte de Dios, de forma que todo es fragmento de un todo divino. Como Raimon Pannikar (2007) refiere, esto puede ser constatado en diferentes libros sagrados (Génesis, Bhagavad-gita, Kaivalya-upanisad) que explican el origen de la vida desde una sola fuente, a la cual si bien se pertenece, esto ha sido olvidado, manteniendo para ello un anhelo inconsciente de volver a la unidad.

En general, esta propuesta conceptual ha sido inspirada tanto en las observaciones hechas en campo, como por las ideas de Panikkar (1999) de «intuición cosmoteándrica», la cual contempla ciertas condiciones fundamentales para la espiritualidad: no puede estar reglamentada puesto que es espontánea; debe mantenerse al margen de ideologías encapsulantes, de forma que se viva de manera particular desde la experiencia de cada sujeto dentro de las especificidades de cada cultura; 5 hay una relación no-dualista entre la Tierra y el ser humano en la que ninguno es superior ni inferior, de forma que sea parte de nuestra autocomprensión; hay que superar la ideología panmonetaria en la que solo se extraen recursos del medioambiente; debemos superar la dicotomía entre el llamado misticismo natural y el misticismo teísta. Sobre este último punto, para Panikkar (1999:180) la naturaleza no es «nada si no es naturata (engendrada) e igualmente, Dios es una abstracción si no es naturans (engendrador)», es decir, se puede encontrar a Dios en los múltiples rincones y manifestaciones de la naturaleza.

En conclusión, la dialéctica panteísta hace alusión a la manera en que los seres humanos podemos crecer espiritualmente a través del diálogo con la naturaleza. Esta comunicación es posible usando algo más que el lenguaje verbal, ya que implica el uso de una amalgama de simbolismos, los cuales parten de combinar la interpretación de fenómenos naturales con la realización de prácticas espiritualmente intencionadas y dirigidas por personas facultadas para ello. Tales per-

\footnotetext{
${ }^{5}$ Panikkar (2007:123) describe uno de los más grandes desafíos a la teología con la siguiente pregunta: ¿es obligatorio abrazar la cosmovisión de alguna de las grandes tradiciones para poderse llamar siervo de Yahweh, hermano de Cristo, seguidor del Profeta (Mahoma)? Es decir, «un africano, un indio, un chino, ¿deben necesariamente desenraizarse del fértil suelo de sus culturas seculares, así como de su pensamiento, de sus mitos y de sus profundas convicciones humanas si se sienten atraídos por estas tres llamadas religiones monoteístas, o por la moderna ideología humanista?»
} 
sonas facilitan tanto el reconocimiento de los mensajes que son dados a través de diferentes manifestaciones de la naturaleza, como las formas en las que nos es posible hacerle explícito nuestro mensaje hacia ella. Como podremos ver, en el caso del pueblo Kaqchikel, la dialéctica panteísta se lleva a cabo en las ceremonias de fuego con la guía de la o el ajq'ij.

\section{Origen del pueblo Kaqchikel}

Si bien a este pueblo le fue dado el nombre de Gagchequeleb según lo señala el Popol Vuh (Recinos 1960:117), eran más conocidos como Kaqchikela'. Al hacer un análisis etimológico encontramos que el nombre Kaqchikel se deriva de la palabra kaqache 'árbol colorado'b, y siendo más específicos encontramos que es el resultado de la combinación de dos vocablos kaq 'rojo' y che' 'árbol'.

Por otro lado, en un fragmento del Memorial de Sololá (Recinos 2013:60-61) se expresa lo siguiente: «Cuando llegamos a las puertas de Tulán fuimos a recibir un palo rojo que era nuestro báculo, y por esto se nos dio el nombre de cakchiqueles, ¡Oh hijos nuestros!». Lo anterior cobra más sentido con base en lo que informa la tradición oral: que se tomó ese nombre al haber hecho el báculo (cha'me'y) — símbolo de poder y autoridad entre este pueblo— de la planta kaqche' antes referida.

Sobre su génesis, los estudios hechos por Thompson (1979:22) y la interpretación de Recinos sobre el Memorial de Sololá (Recinos 2013), nos hacen suponer que los kaqchikela', al igual que los k'iche' y los tz'utujiles, tienen entre sus ancestros a los Maya' itzaes —identificados a su vez con los putunes- provenientes del sur de Campeche y Tabasco, los cuales habitaron en la península de Yucatán. Dicho grupo entró en contacto con emigrantes toltecas,? seguidores de Quetzalcóatl, que se asentaron y revitalizaron cerca del 987 d.C. la antigua ciudad de Chichén Itzá.

El Memorial de Sololá (Recinos 2013:17) plantea que el pueblo Kaqchikel cohabitó pacíficamente junto con el pueblo K'iche'. Si bien dicha coexistencia beneficiaba a ambos, se mantuvieron sus particularidades, en especial las lingüísticas y religiosas. Por ejemplo, los linajes k'iche' y los achi' tenían un mismo dios de nombre Tohil, mientras los kaqchikela' tenían a Chamalkan (hermosa serpiente).

${ }^{6}$ En los registros hechos por Ximénez (1985) podemos encontrar la variante kaqche', sin la vocal epeténtica «a», puesto que de otro modo sería «kaqachekel».

${ }^{7}$ Clavijero (1979:51) sugiere que los toltecas emigraron a raíz de una crisis ambiental en el año de 1052 a diferentes lugares, entre ellos Yucatán y Guatemala. 
Un evento que unió inicialmente a ambos pueblos fue el control del fuego por parte de los kaqhikela'. En esta parte aflora una primera muestra del sentido de resistencia por parte de los kaqchikela'. Según el Popol Vuh (Recinos 1960:115): «no pidieron el fuego los kaqchikeles porque no quisieron entregarse como vencidos, de la manera como fueron vencidas las demás tribus cuando ofrecieron su pecho y su sobaco para que se los abrieran». Esta resistencia favoreció que el pueblo K'iche' les respetara. Esto fue así hasta que durante el reinado del señor Kika'ab (1417) sus hijos Tata Yak y Aj Itza' se sublevaron ante la negativa de parte de su padre de actuar con mayor soberbia frente a las otras tribus, entre ellas el pueblo Kaqchikel. El día trece iq del mismo año, Kika'ab habló con los señores kaqchikela' de las siete tribus y les aconsejó que buscaran un nuevo asentamiento en el cerro Ratzamut (Memorial de Sololá, Recinos 2013:98-101). Ahí el Ajpop Sotz'il Jun Toj y el Ajpop Xajil Wuqu' B'atz' fundaron en 1470 la que sería la gran ciudad de Iximche'. ${ }^{8}$

A raíz de este triunfo, los kaqchikela' se adueñaron de varias ciudades anteriormente k'iche', como Xechibohoy, Xechituh, Quitzqab, Xechith, Chakihyá y Xivanu'l, ampliando así significativamente su territorio. De hecho, esta expansión llevó a que a principios del siglo XV el territorio kacqhikel abarcara lo que actualmente es casi todo el departamento de Chimaltenango, el departamento de Sacatepéquez, incluyendo además la parte noroccidental del departamento de Guatemala, un pedazo del noreste de Suchitepéquez, el norte de Escuintla y la parte norte del Lago de Atitlán. En total cerca de 8000 km² (Polo 1977).

\section{LA PROLONGADA Y VIGENTE RESISTENCIA ESPIRITUAL KAQCHIKEL}

Desde hace siglos no ha cabido duda de que el saqueo era el móvil detrás de la conquista de América (Sahagún 2006). En el caso de Guatemala, en los Títulos de la Casa Ixquín-Nehaib, Señora del Territorio de Otzayá, se refiere que desde 1512 llegaron noticias a la región del desembarco de los españoles, de lo cual los kaqchikela' ya estaban al tanto. Cuando estos se enteraron de la caída del imperio azteca en 1521, convinieron en sacar provecho de una posible alianza con los extranjeros a fin de eliminar a sus enemigos k'iche' y tz'utujila'. Después de establecer la alianza, al ver los kaqhikela' las atrocidades que los españoles cometían y debido a los enormes tributos que les exigían, se sublevaron bajo el

${ }^{8}$ Guillemin (1980) concluyó que esa era el año de la fundación, aunque existe la posibilidad de que haya sido algunos años después. 
Imagen 1. Panorámica actual de Iximche'.

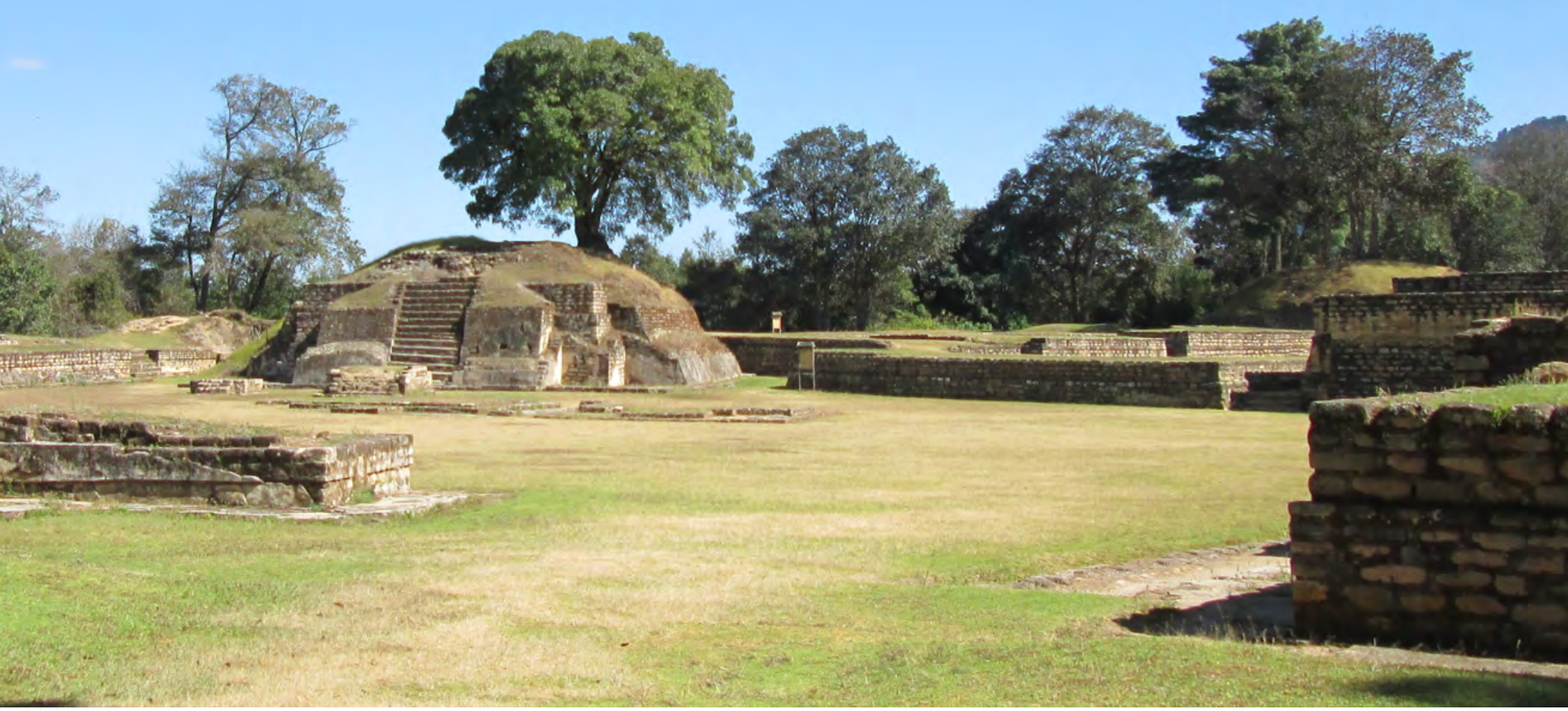

liderazgo de Kaji' Imox (Memorial de Sololá, Recinos 2013:124), peleando durante 10 años, hasta 1540.

Después de la conquista, se señaló todo símbolo de la espiritualidad indígena como un acto del demonio. Esto implicó una profunda contradicción detectada por los pueblos sojuzgados, hecho descrito en el Chilam Balam donde se enjuicia a los españoles con los criterios de la doctrina que ellos mismos practicaban: «Nos cristianizaron, pero nos hacen pasar de unos a otros, como animales. Dios está ofendido de los chupadores [...] Este Dios Verdadero que viene del cielo, solo de pecados hablará, solo de pecado será su enseñanza, inhumanos serán sus soldados, crueles sus mastines bravos».

Pero estas estrategias lograron escasamente erradicar las creencias y prácticas indígenas, las cuales más bien se fusionaron con los elementos más básicos del 
catolicismo que pudieran presentar similitudes con la espiritualidad autóctona, ${ }^{9}$ como sería el caso del santoral católico fusionado con las divinidades mesoamericanas. Pese a ello, de cualquier manera prevaleció el rechazo:

Los indios generalmente se conservan en su idolatrías antiguas, y su cristianismo no es más que apariencia e hipocresía [...] tienen a los españoles y ladinos por forasteros y usurpadores de estos dominios, por cuyo motivo los miran con odio implacable y en lo que los obedecen es por puro miedo y servilismo. Ellos no quieren cosa alguna de los españoles, ni la religión, ni la doctrina, ni las costumbres (Cortés y Larraz 1958).

Por lo tanto, la resistencia a subsumirse era un código que orientaba la acción. Destaca en Los Títulos de la Casa Ixquín-Nehaib (Recinos 1957) un fragmento que puede ilustrarlo: «comenzó nuestra matanza por parte de los hombres de Castilla [...] la muerte nos hirió nuevamente, pero ninguno de los pueblos pagó el tributo». Y es que, tal como reconocieron cronistas de la época como fray Bernardino de Sahagún, fray Bartolomé de las Casas y fray Francisco Ximénez, la resistencia a la conquista espiritual se mantuvo, pudiendo decir que la espiritualidad indígena prevaleció y solo incorporó o adaptó aquello que le convino de lo católico. ${ }^{10}$ Fuentes y Guzmán $(1932: 156,275)$ lo expresa dentro de la Recordación Florida: «Bastaba la acción del arado en la superficie de la tierra para que de ella brotaran, como por ensalmo, figurillas paganas de toda clase».

Es importante que se reconozca esta situación como una herencia de opresión que sigue sometiendo física y mentalmente a una gran parte de la población indígena de Guatemala. Es decir, hay que mirar el dolor de ese pasado lleno de antagonismos raciales, los cuales dieron paso en gran medida al genocidio durante la Guerra Civil en Guatemala (1960-1996). De hecho, Martínez (1998) plantea que la colonización y el sometimiento no se detuvieron con la pretendida independencia de España, ya que para la mayor parte de la población indígena esto no significó cambio alguno. Posteriormente, la opresión se mantuvo y se acentuó durante el conflicto armado entre 1960 y 1996, cobrando miles de vidas

\footnotetext{
9 Bartolomé de las Casas (2004:73) da una explicación sobre ciertas similitudes que dijo haber encontrado, dando incluso un supuesto testimonio de un señor principal quien le explicó que en su creencia también había un Padre, un Hijo y un Espíritu santo "el Padre se llama Izona, que había criado a los hombres y todas las cosas: el Hijo tenía por nombre Bacab, el cual nació de una doncella siempre virgen, llamada Chibirias, que está en el cielo con Dios».

10 Un suceso que puede ampliar la compresión de ese sincretismo a conveniencia, cuyas adaptaciones eran expresión de resistencia, fue lo acontecido en los pueblos de San Juan Chamula y San Juan Cancuc, Chiapas, en 1710 y 1712, respectivamente (García de León 1985).
} 
de indígenas (250000 según la Comisión para el Esclarecimiento Histórico). Dicha guerra tenía en uno de los lados al Estado guatemalteco, empeñado en exterminar a lo que se considerara fuera de la llamada «Guatemala útil» (Le Bot 2013).

Imagen 2. Trabajo psicosocial de un ajq'ij en fosas comunes usadas en la época de la Guerra Civil

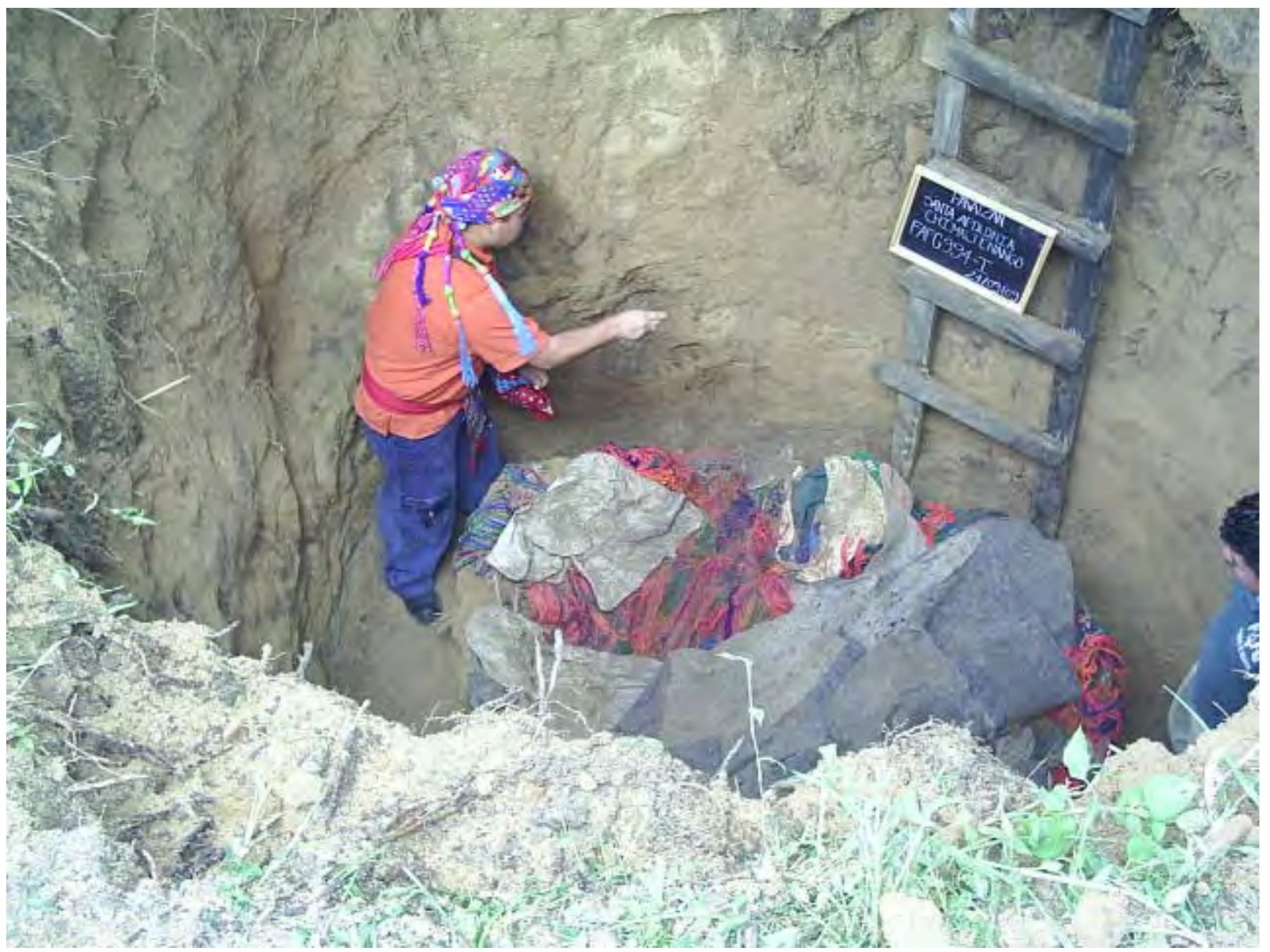

LA ESPIRITUALIDAD KAQCHIKEL COMO UNA PRÁCTICA COLECTIVA

Retomando lo ya expuesto sobre el Nimab'äl K'u'x, las y los aja'ija' consultados plantean que en la cosmovisión Kaqchikel (CK) el ser humano se vivencia a sí mismo como "parte de un todo, sin barreras existentes entre los seres humanos, la naturaleza y el universo». De hecho, es este punto una diferencia sustancial reco- 
nocida respecto de la racionalidad occidental. En ella «se establecen jerarquías [...] los seres humanos son considerados superiores al resto de la naturaleza». Esa visión antropocéntrica podría ser vista como una «barrera mental que llena de prejuicios la relación entre los humanos y la naturaleza» de forma que «el interés humano se cree que debe gobernar todos los fenómenos y a todos los seres».

Por otro lado, para las y los ajq'ija' en la CK existe un amplio rango de valores, entre estos la tolerancia hacia lo que la otra concepción considera «malo». Es decir, «todo lo creado tiene su razón de ser y no puede explicarse desde nuestra lógica humana». Por lo tanto, para la CK hay luz en la oscuridad, pero también existe oscuridad en la luz: "La semilla necesariamente tiene que morir para hacer surgir una nueva vida. De la noche oscura nace el día y del dolor surge la trascendencia».

A continuación se ahondará en las categorías anunciadas al inicio, integrando la explicación de distintos simbolismos que permitan comprender el sentido y funcionamiento del cosmos para el pueblo Kaqchikel.

\section{a. EI TIEMPO}

El tiempo va mucho más allá de la simple medición de espacios, ciclos y periodos, o del transcurrir de la vida o de la existencia. Tiene una connotación mística, que es determinante para el establecimiento de momentos y espacios apropiados para la práctica de actividades rito-ceremoniales. Su comprensión implica reconocer la existencia de tiempos específicos, favorables y adversos, para la realización de actividades. Tal sería el caso del tiempo propicio para la fecundación humana, animal y vegetal; el periodo adecuado para la iniciación o finalización de actividades individuales, familiares o colectivas, cuestión que también incide en la dimensión social, económica y política.

Al hablar de los tiempos favorables y adversos, estamos refiriéndonos a las distintas manifestaciones que puede tener la vida. Por referir algunos de los que nos fueron enunciados, están: el Sol con su parte contraria, el periodo de sombra; el periodo de lluvia con periodos de sequía; los periodos de alegría con los periodos de tristeza; los periodos de salud con los periodos de enfermedad.

Para entender lo anterior hay que tener presente el principio de equilibrio, que nos lleva a «saber esperar». Las y los ajq'ija' enfatizan mucho este punto al decir que: «el tiempo no se pierde, el tiempo no se ahorra, el tiempo no se gana». Al contrario, «el tiempo es una forma en la cual se manifiesta el sentido de nuestra 
vida» mediante la concatenación de sucesos, lo cual «lo podremos ir comprendiendo, a través del apoyo de soportes espirituales como los calendarios y la observación de nuestros rasgos positivos y negativos según las energías de los wäch q'ij (energías, conocidas tambien como nawali) que nos influyan».

En cuanto a los calendarios, ${ }^{11}$ el ha'ab' o calendario solar, se configura en relación con el movimiento de la Tierra alrededor del Sol. «Este calendario es otro de los mayores logros desarrollado por el talento de Nuestros Abuelos, ya que integra tres calendarios: cósmico, físico y espiritual». Comprende un total de 365 días que se obtienen a partir de multiplicar 18 meses con un total de 20 días cada uno, con el agregado de 5 días extras de silencio o reacomodo conocido como Wayeb.

Imagen 3. Organización de las 20 energías de los wäch q'ij.

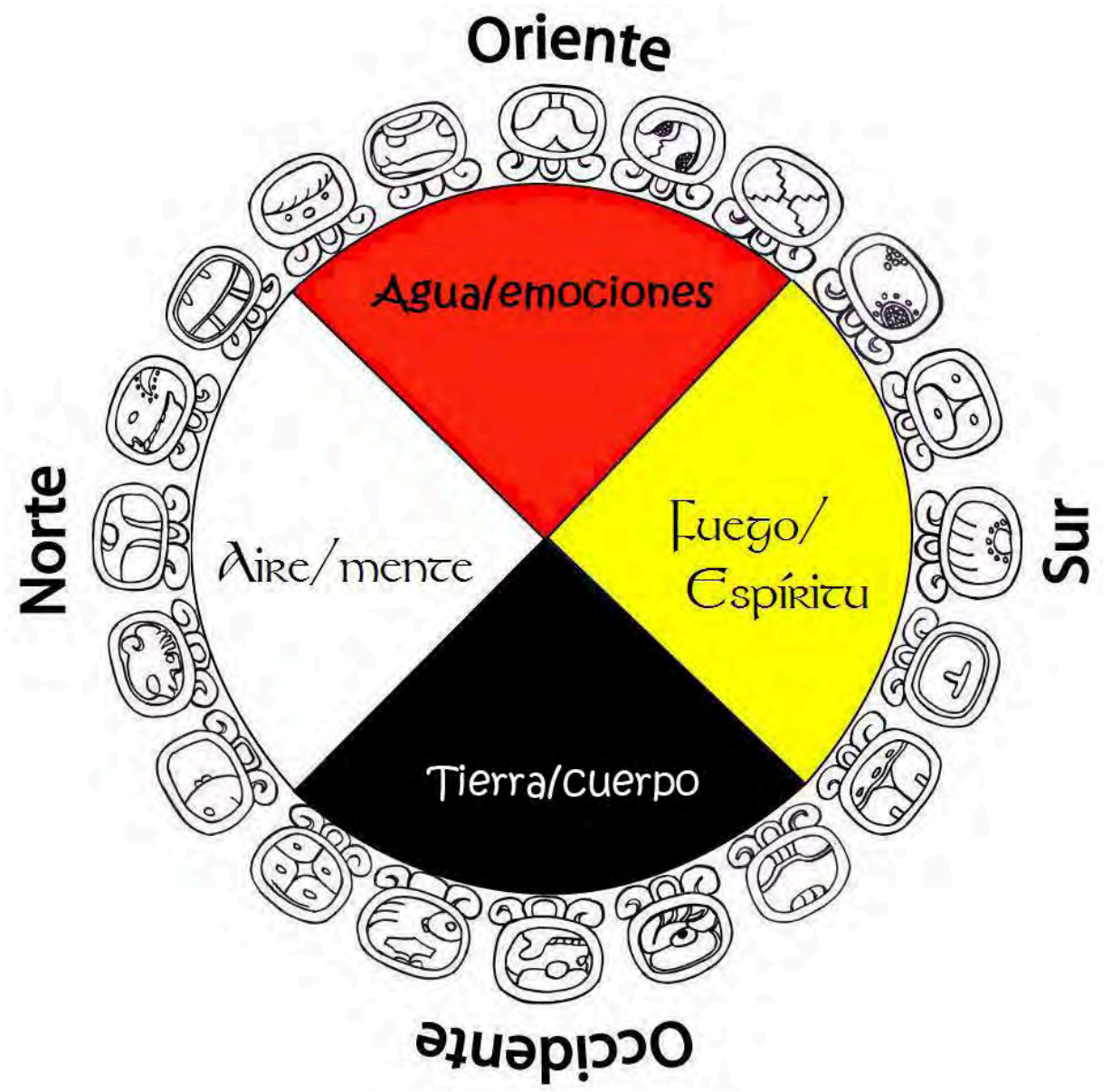

${ }^{11}$ Fray Diego de Landa (1985) fue la primera persona de la cultura occidental que intentó hacer una interpretación del calendario solar, haciendo énfasis en lo que identificó como los momentos más importantes: el nacimiento, el casamiento, el poder político, los rituales funerarios, entre otros. Otro análisis más reciente lo encontramos por ejemplo en Friedel et al. (1999). 
Otro calendario importante es el Cholq'ij o calendario lunar, configurado en relación con el movimiento de la Luna alrededor de la Tierra. Este último es el que más uso tiene en la actualidad, y consta de 260 días agrupados en 13 meses de 20 días cada uno (véase cuadro 2). La combinación de ambos calendarios nos lleva a comprender el origen de los periodos de 52 años que se manejaban entre varias de las culturas mesoamericanas (Clavijero 1979). Y es que la yuxtaposición del calendario de 365 días con el de 260 días hace que los calendarios coincidan en el mismo día y el mismo número cada 52 años, después de haber transcurrido 18989 días. Esto equivale a 73 vueltas de 260 días o 52 vueltas de 365 días. A esto se le suele llamar «Rueda calendárica».

A través de los calendarios cada persona puede «conocer sus virtudes y áreas en las que debe trabajar. Al conocerlas la persona sabe si puede desempeñar determinado oficio, rol o responsabilidad dentro de una sociedad». Es así que, más que reducir al individuo a una máquina productora, «se trata de que cada persona encuentre su riqueza espiritual-humana, porque el humano es espíritu materializado, para que la retransmita a sus demás hermanos y hermanas en el planeta». ${ }^{12}$

\section{b. EL TERRITORIO}

Partiendo del principio de integración e interdependencia, para la CK el territorio debe ser visto por los seres humanos como algo sagrado y no como una fuente de extracción de recursos para fines comerciales o económicos. Es decir, «se debe buscar la integralidad entre el fluir humano-humano, humano-territorio, territorio-cosmos y territorio-humano-cosmos». Esto se relaciona con la comprensión del territorio como una «totalidad viva a través de la cual se manifiestan las energías creadoras».

El hecho de que se le defina como una totalidad viva tiene que ver con que todos los elementos de la naturaleza tienen Ruk'u'x 'corazón' y su Rajawal 'guardián'. Eso nos pone en una posición de igualdad frente a todos los seres, tangibles e intangibles, a los cuales se les debe tener respeto: «Los mares, los océanos, los cerros, las montañas, las cuevas, los rincones de los bosques, los ríos. Lo tangible e intangible tienen razón de ser, tienen su función y también sus guardianes, que pueden ser humanos, animales y seres invisibles».

12 Esta interacción con otros seres vivos está muy clara en el Popol Vuh (Recinos 1960:103) y en el Memorial de Sololá (Recinos 2013), donde se le da un papel central a los animales como orientadores del camino del ser humano. 
Destaca la comprensión del territorio no son solo como los elementos que coexisten físicamente, sino como espacio que se distingue por la historia de quienes lo han habitado. En este punto puede mirarse con claridad la constelación de la existencia ya explicada, y es que, según lo expuesto por un miembro del Consejo Kaji'-Imox- B'eleje' K'at, «todo territorio habitado tienen su historia y tiene un significado en la memoria de cada uno de quienes lo han habitado desde tiempos remotos, y porque de esa manera es que se han convertido en la historia oral de los pueblos».

Esa historia se encuentra contenida en la forma de los conocimientos que los pueblos tienen sobre el sentido y uso de los elementos del territorio. Esto lo podemos encontrar en la diferenciación que hacen las y los ajq'ija' entre la medicina tradicional Maya'y la alópata u occidental:

Imagen 4. Vista panorámica del Lago de Atitlán

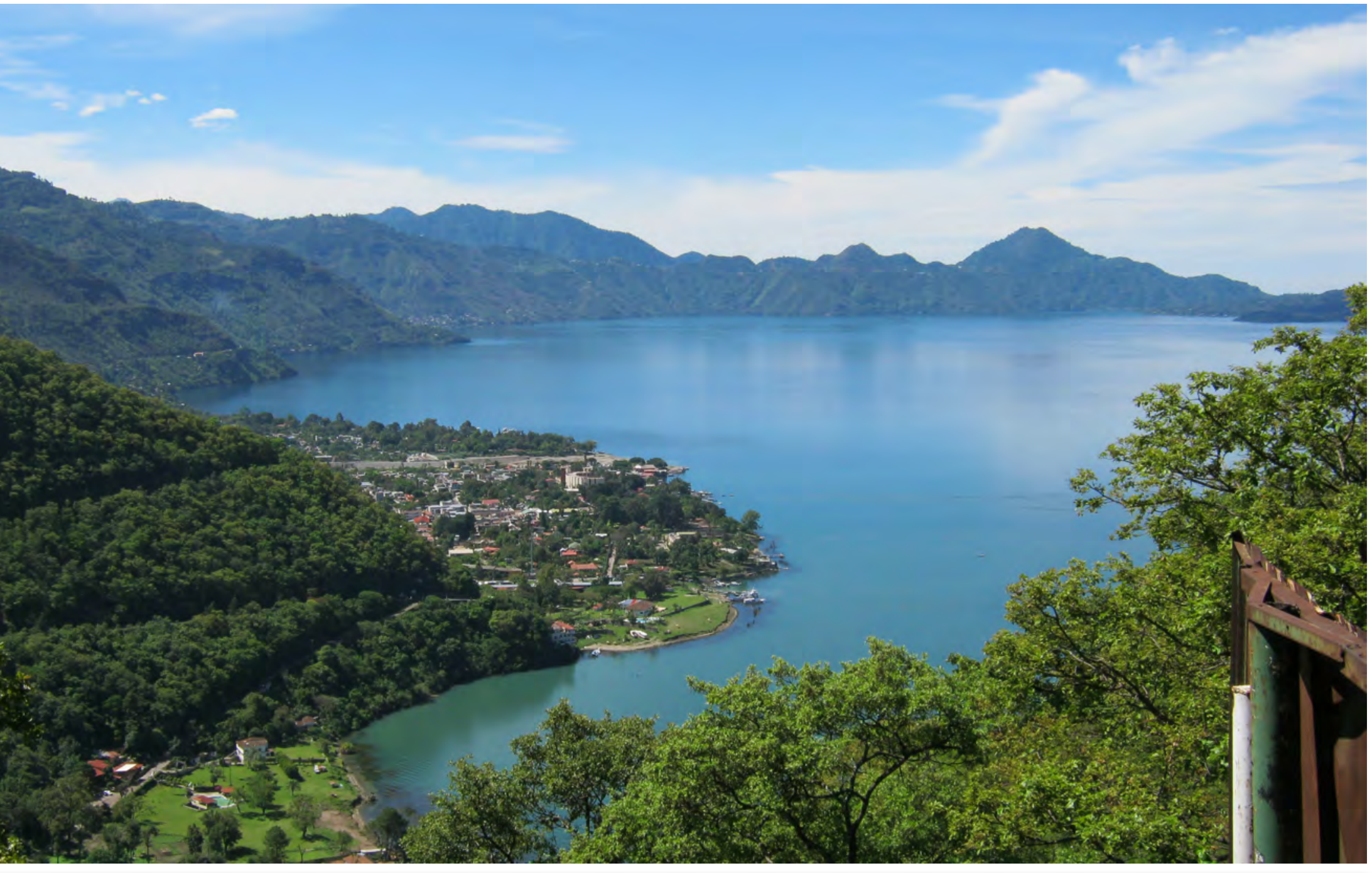


La globalización de las medicinas y prácticas tradicionales pone en riesgo la territorialidad porque irrumpe el espacio de quienes han mantenido la dinámica por generaciones y por miles de años en los distintos territorios. [...] Es distinta la dinámica cuando un invitado de otra tradición se le pide compartir su medicina. El conocimiento que se comparte conlleva el movimiento de energías, y cuando se irrumpe un territorio sin tomar en cuenta el protocolo local, se genera el riesgo de dejar un caos que los locales deben re-ordenar porque se abren puertas dimensionales que no dejan cerradas por no saber hacerlo.

\section{c. LA COMUNIDAD}

Según la definición de uno de los ajq'ija' consultados la comunidad sería «un grupo de personas dentro de un territorio demarcado por un idioma, parentesco o interés común en el que tiene que ver todo lo que existe en el medio». Ese conjunto de personas que participan dentro de la colectividad asumen ciertos roles que dan sentido a la interacción entre los diferentes sujetos. Esto es fundamental, se reconoce que en caso de no haber esos roles o responsabilidades para con los demás, por más que vivan muchas personas juntas no podría haber comunidad: «es diferente en la ciudad, allá no se relacionan con respeto mucho las personas, entonces no hay comunidad como aquí, porque es raro que haya ayuda mutua».

Imagen 5. Consejo en proceso de toma de decisiones

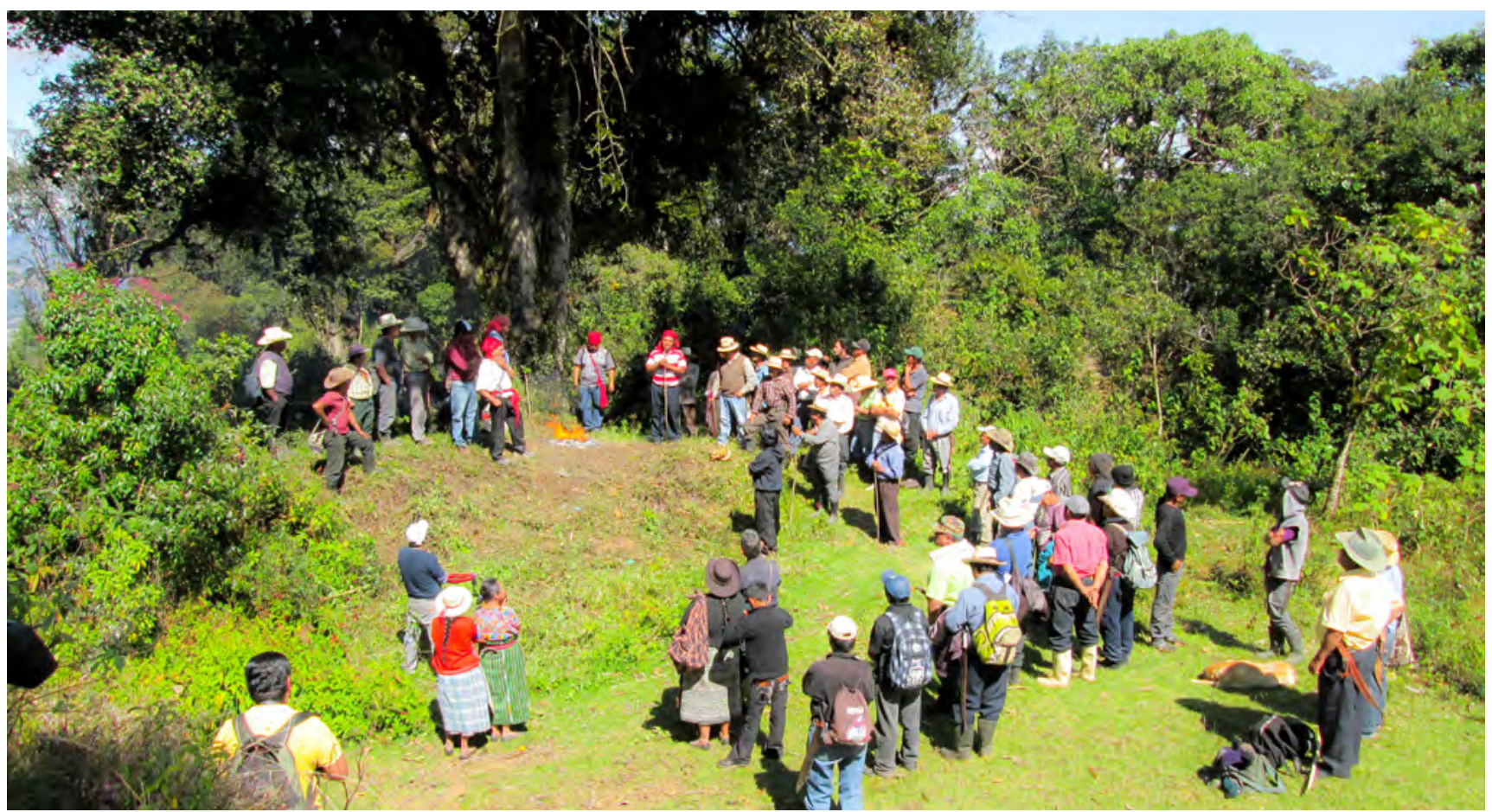


Todos los roles implican un servicio orientado por valores culturales, y están implícitos en la estructura social, como es ser madre o padre, o bien en otros que son exclusivos de ciertas personas. De los primeros nos limitaremos a describir el sentido de ser abuelo y abuela. Ellos y ellas son uno de los roles más importantes, puesto que son quienes guardan y comparten la sabiduría. Por esa trayectoria tienen autoridad moral a nivel tanto familiar como comunitario, de forma que estas personas, al acompañar la toma de decisiones, fortalecen el cuidado y respeto de los principios, valores y normas.

Sobre los roles más exclusivos, a continuación los describimos en términos generales:

Ajq'ij: Dicho sujeto es quien articula la armonía entre la comunidad y ese otro mundo espiritual, restableciendo la salud y la armonía cósmica a través de complejos rituales que vinculan lo social y lo psicológico, de forma que el individuo siempre se define en función de lo grupal-sociedad. También tiene la obligación de cuidar los lugares sagrados, porque «dichos espacios son los que mantienen el equilibrio energético de la Madre Tierra y todos los demás seres».13

Aq'omanela' (médicos): son las personas que aplican sus conocimientos en la salud curativa y preventiva, basándose en plantas, minerales, animales, frutas, hongos, etc. Dichas autoridades son las encargadas de orientar, educar, prevenir y curar a las personas, siendo esencial en esa educación el inculcar y recordar la importancia del respeto a los elementos de la naturaleza: el agua, aire, tierra, plantas, animales y a los cuidadores invisibles de naturaleza.

$K^{\prime}$ exeloma': médicas parteras, ${ }^{14}$ quienes han sido consideradas a nivel histórico como guerreras de la vida, teniendo además el trabajo de formación de los niños y niñas para que conozcan las plantas medicinales. Ellas también propician la educación para mantener el equilibrio ecológico, la convivencia y el bienestar social de las personas y la madre naturaleza.

Chinamital (Principales): entre ellos se consultan, analizan y buscan los acuerdos favorables para el beneficio colectivo. De hecho, cuando se logra la partici-

${ }^{13}$ Este rol que identificamos como una de las formas en las cuales el pueblo Kaqchiquel busca preservar o restablecer el equilibrio con la naturaleza, también puede ser ubicado en el conocido como hmen en muchas comunidades de origen Maya' en la península de Yucatán (Thompson 1979).

${ }^{14}$ Su importancia era tal, que Sahagún (2006:32) informa que las mujeres que morían en el parto eran consideradas dioses llamadas Cihuapipiltin. Además entre los aztecas existía una divinidad específica para las parteras, conocida como Ciuacóatl, mujer serpiente, Ilamada también Quilatzli. La consideraban una diosa de la guerra, puesto que las mujeres corrían peligros para dar combatientes a la nación. Para los pueblos Maya' esta deidad es identificada con el nombre de Ixmukane'-lxchel. 
Imagen 6. Aq'omanela'.

pación colectiva se observa la conexión que las personas tienen con su entorno a través de la sencillez con que expresan su pensamiento, la dinámica con que se interrelacionan entre personas y entre estas y el entorno natural.

Finalmente, la importancia de la comunidad también puede palparse en la existencia de palabras con la que se alude al espacio colectivo en el que se toman decisiones comunitarias, como sería Nimchomnik (k'iche) o Ch'ob'onik (kaqchikel). Como éste, otros conceptos más serán analizados en el siguiente apartado sobre el idioma.

\section{d. EL IDIOMA}

El idioma es fundamental para conocer a profundidad los conceptos, íconos, valores, principios y gran parte de la gama de facetas que la cultura ha alcanzado. La relevancia de lo anterior reside en que

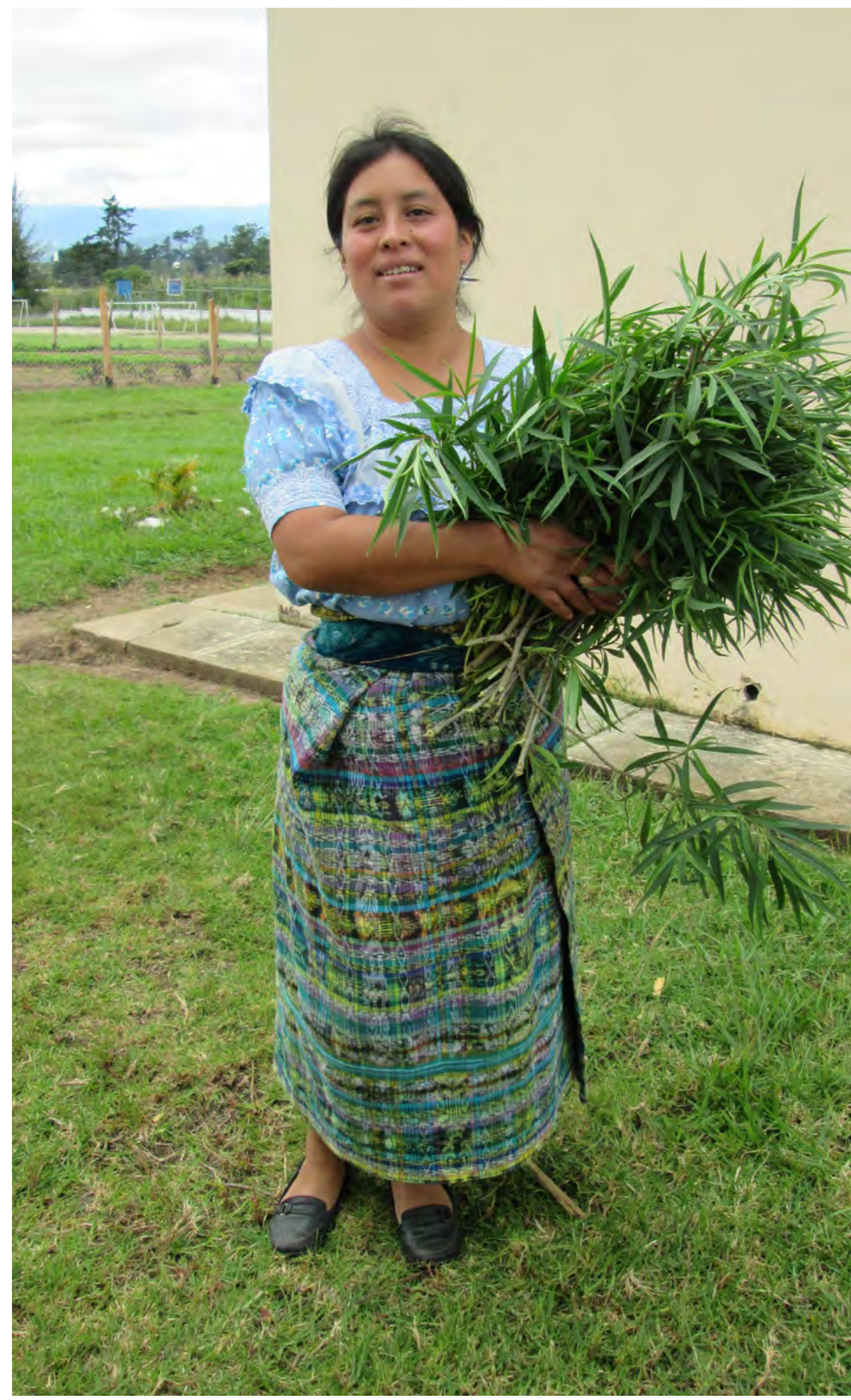
la comprensión de la constelación del sentido de la existencia dentro de los conocimientos culturales se dificulta si solo se recurre a la traducción de palabras aisladas de un contexto. Según los y las ajq'ij'a' debido a que se puede obviar o ignorar la connotación 
energética que posee el idioma en el momento de la conexión con la divinidad. Por ejemplo, en el momento de los fuegos ceremoniales, al usar los términos adecuados en conjunción con otros elementos, se considera que el fuego como tal deja de ser una mera combustión bioquímica y se convierte en una ceremonia con poder, puesto que tienen implícita una plena conciencia, por parte del ajq'ij, del alcance y sentido de lo que está diciendo.

A fin de ilustrar la particularidad de esta cultura, habremos de mirar el caso de algunos valores kaqhikela'. Por ejemplo, lo que en castellano podría ser definido con el término 'servicio' o 'solidaridad', en kaqchikel va más allá, ya que con la palabra paq'uch se alude al trabajo colectivo con un sentido de apoyo, lo cual es una expresión de otro valor fundamental: poqonab'alil. Este término, si bien podría ser traducido como 'solidaridad', trasciende el apoyo entre seres humanos, ya que también implica un servicio hacia todos los seres que habitan en el territorio. A su vez este concepto se conecta con otro que es tz'aqatil y que nos explica el principio de complementariedad, ya que nadie puede vivir solo, de forma que para poder interpretar la totalidad hay que aceptar que los polos opuestos no son antagónicos, y que cuando se tiene el corazón abierto se genera compatibilidad y conciliación (cuadro 1).

\section{e. EL LOQ'OLÄJ Q'AQ' (FUEGO SAGRADO)}

La ceremonia Maya' es la actividad sagrada a través de la cual el ser humano busca acercarse y comunicarse con el Ser Supremo, el Creador del Cielo y de la Tierra, con los wäch q'ij y los elementos tierra, fuego, agua, aire; con los ancestros y los guardianes del bosque, de las cuevas, mares, lagos, etc. Asimismo, las ceremonias Maya' se llevan a cabo con objetivos muy concretos, ya sea para inaugurar y celebrar fechas importantes, rendir ofrendas como muestra de agradecimiento, para pedir bienestar físico, para la salud mental y espiritual, para el trabajo y la sabiduría en momentos difíciles o para pedir protección. En general, se busca llenarse de energía positiva y limpiarse de las negativas. 
Cuadro 1. Valores del pueblo Kaqchikel.

\begin{tabular}{|c|c|c|c|}
\hline Valor & Traducción & Significado & Antivalor \\
\hline Paq'uch & $\begin{array}{l}\text { 'Reciprocidad' } \\
\text { (Tu alegría es mi alegría) }\end{array}$ & $\begin{array}{l}\text { Trabajo colectivo, trabajo en Equipo } \\
\text { con un sentido de apoyo }\end{array}$ & Yonilk'aslem 'Desvinculación' \\
\hline Pogonab'alil & $\begin{array}{l}\text { 'Solidaridad' } \\
\text { (Tu dolor es mi dolor) }\end{array}$ & Servicio a los seres dentro del territorio & Kow K'uxal 'Indiferencia' \\
\hline Ttz'aqatil/K'ulanik & 'Complementariedad' & $\begin{array}{l}\text { Tener aceptación de la } \\
\text { interdependencia entre todos los seres }\end{array}$ & Ch'aronik 'Fragmentación' \\
\hline$K^{\prime} a x k^{\prime} O l$ & 'Servicio comunal' & $\begin{array}{l}\text { Trabajar para los demás como parte del } \\
\text { compromiso de la vivencia colectiva }\end{array}$ & Mek'is Tzij 'Irresponsabilidad', 'Pereza' \\
\hline Kab'awilal & 'Dualidad' & $\begin{array}{l}\text { Reconocer que todos somos la } \\
\text { combinación de físico y espiritual }\end{array}$ & Ch'aronik 'División Incompatibilidad' \\
\hline Xajanb'äl & 'Respeto' & $\begin{array}{l}\text { Todo es posible, pero no todo es } \\
\text { permitido. El respeto emana del amor }\end{array}$ & Mek'is Tzij 'Soberbia' \\
\hline Pak'ex & 'Intercambio' & $\begin{array}{l}\text { La práctica del libre intercambio de } \\
\text { conocimientos y productos }\end{array}$ & Mün 'Avaricia' \\
\hline $\begin{array}{l}\text { Cholwajonem } \\
\text { Junamil K'u'x }\end{array}$ & 'Equilibrio y armonía' & $\begin{array}{l}\text { Tomar decisiones basándose en el } \\
\text { mutuo acuerdo, sin destruir otros } \\
\text { procesos positivos }\end{array}$ & Mepab'nik'Desarmonización' \\
\hline Räxnaqil & 'Humildad' & No considerarse superior a los demás & Mena'/Mek'is Tzij 'Egoísmo' \\
\hline Pixab'anik & 'Dar y recibir consejo' & $\begin{array}{l}\text { Búsqueda de soluciones pacíficas } \\
\text { mediante el diálogo y la escucha activa }\end{array}$ & Mek'is Tzij 'Irrespeto' \\
\hline Loq'ob'enik & 'Sacralidad de la vida' & $\begin{array}{l}\text { Valorar todos los aspectos de la vida y } \\
\text { todo lo que se recibe }\end{array}$ & Mek'ax 'Ignorancia' \\
\hline Chajinik & 'Cuidado de lo existente' & $\begin{array}{l}\text { Respeto de la vida y se aplica al pedir } \\
\text { permiso a las autoridades comunales o } \\
\text { a los guardianes }\end{array}$ & Telechanem 'Explotación' \\
\hline Pach'uj $\mathrm{Na}^{\prime} \mathrm{oj}$ & 'Consenso' & $\begin{array}{l}\text { Que ninguno se quede detrás de los } \\
\text { demás. Caminar unidos para articular } \\
\text { fuerzas entre todos las personas }\end{array}$ & Ch'aronik 'Fragmentar' \\
\hline K'ulb'enik & 'Consulta y diálogo' & $\begin{array}{l}\text { La escucha y uso de la palabra a nivel } \\
\text { familiar y comunitario para lograr } \\
\text { acuerdos }\end{array}$ & Oyowal 'Agresión verbal y física' \\
\hline Ruq'ii qatzij & 'Palabra de honor' & $\begin{array}{l}\text { Compromisos de vida y de dignidad } \\
\text { al hablar }\end{array}$ & Tz'uknel Tzij 'Mentira y engaño' \\
\hline Ajowanik & 'Amarse a uno mismo' & $\begin{array}{l}\text { Tener buena autoestima y mantener la } \\
\text { vitalidad del espíritu en el cuerpo }\end{array}$ & Itzel 'Mala persona que hace daño' \\
\hline
\end{tabular}

Fuente: elaboración propia. 
Imagen 7. Material ceremonial

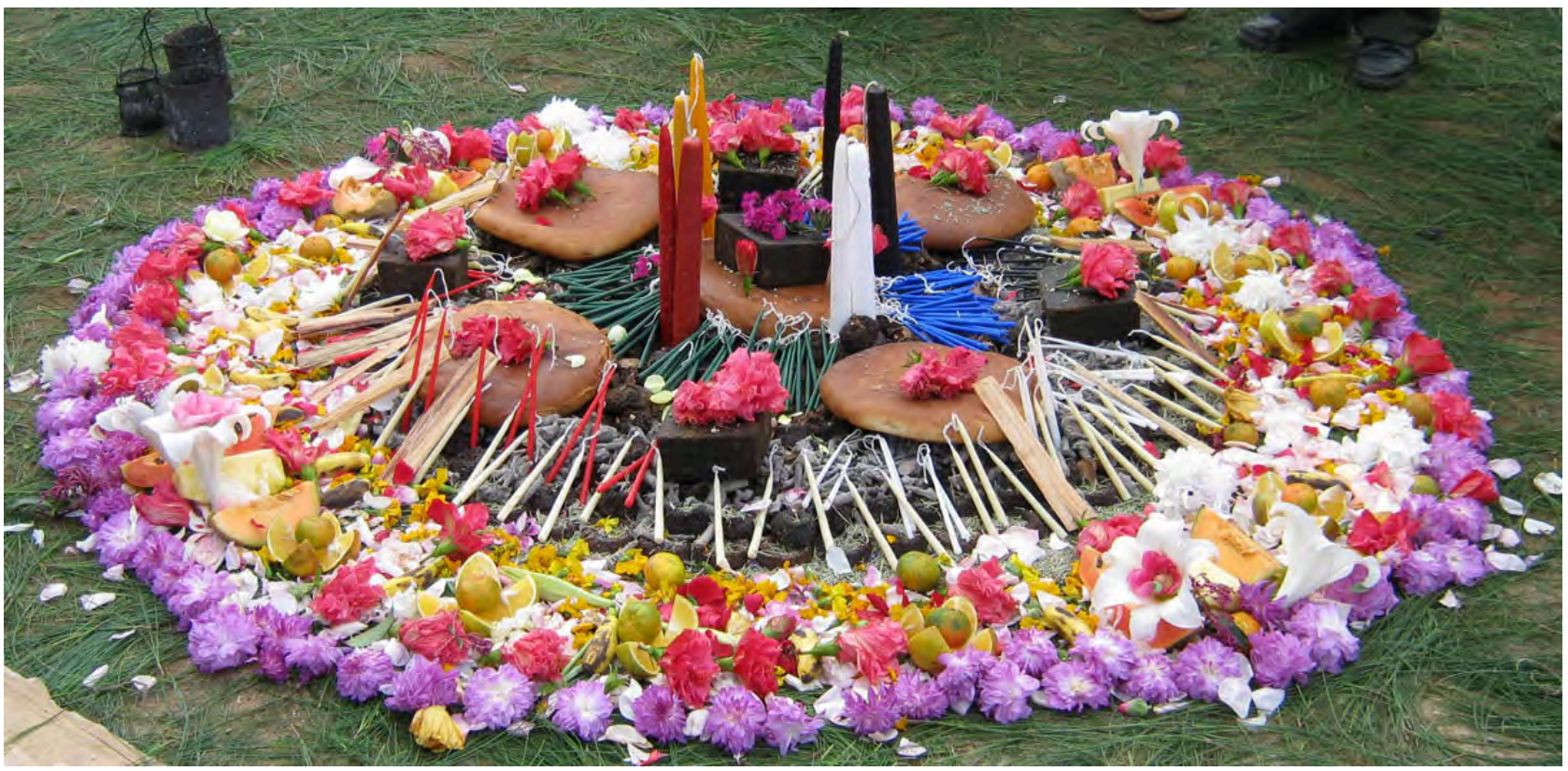

Imagen 8. Acompañamiento psicosocial

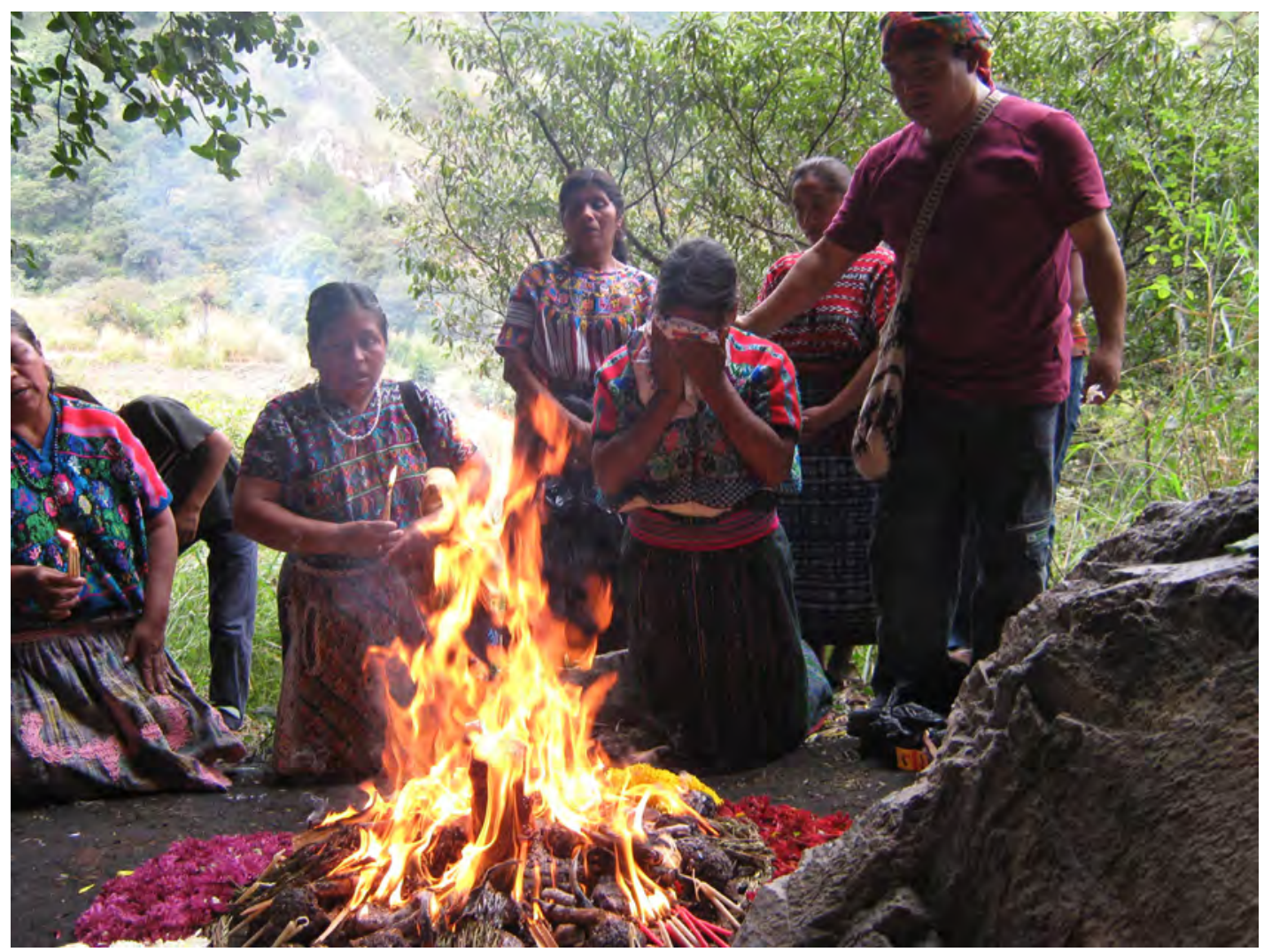


Estas ceremonias son practicadas en lo que se conoce como «Altares o Lugares Sagrados», ubicados en cerros y otros sitios considerados vestigios de los antiguos Maya', aunque también pueden celebrarse en áreas en donde concurra una cantidad de personas que estén de acuerdo en celebrar un momento como tal, ya sea en casa, en los sembradíos, etc. El elemento fundamental en la ceremonia Maya' es el Sagrado Fuego, el cual se genera a través de la ofrenda de diferentes materiales como incienso, copal, panela o azúcar, velas o candelas de colores, flores, tabaco y otros materiales. De hecho, es a través del Fuego como el Ser Supremo, las abuelas y abuelos, los cuidadores, los elementos en todas sus manifestaciones se comunican con el ajq'ij y con todos los participantes.

La manera de acomodar los diferentes elementos es basándose en un símbolo de suma importancia cultural, que es la cruz Maya'. Cabe señalar que esta no tiene su origen en el sincretismo con el cristianismo (De las Casas 2004:72), sino que desde tiempos inmemoriales se utilizó para representar tanto los puntos cardinales como las cuatro esquinas de la tierra y del universo (véase imagen 3). El uso de la cruz en las ceremonias reproduce el orden en la creación del mundo, y cada dirección tiene un significado complejo.

Cuadro 2. Simbolismos y significados en el Fuego Sagrado.

\begin{tabular}{|l|l|l|l|l|l|l|}
\hline \multicolumn{1}{|c|}{ Orientación } & Salida del Sol & Caída del Sol & Salida del viento & Caída del viento & \multicolumn{1}{|c|}{ Cielo } & Tierra \\
\hline Relación Humana & Sangre & Cabello & Huesos & Líquido Bilis & Espíritu & Físico \\
\hline Color de Maíz & Rojo & Negro & Blanco & Amarillo & Azul & Verde \\
\hline Elemento & Agua & Tierra & Aire & Fuego & Enegía & Materia \\
\hline Abuelo & B'alam K'itze' & B'alam Aq'ab' & lq' B'alam & Maj Uk'utaj & $\begin{array}{l}\text { Ruk'u'x } \\
\text { Kaj }\end{array}$ & \begin{tabular}{l} 
Ruk'u'x Ulew \\
\hline Abuelas
\end{tabular} \\
\hline $\begin{array}{l}\text { Otras } \\
\text { asociaciones }\end{array}$ & Kaja' Paluna' & Chomija' & Kaqixaja' & Tz'ununija' & & \\
\hline
\end{tabular}

Fuente: Elaboración propia.

Una prueba del sentido sagrado de las matemáticas lo podemos constatar al ver que al trazar líneas para generar cuadros en el interior de la cruz tendremos el resultado de 13 cuadros (véase imagen 9), las cuales representan las 13 conste- 
laciones y las trece articulaciones mayores en el ser humano. Asimismo, al contar las esquinas en todo el contorno de la cruz, encontraremos un espacio para cada uno de los 20 rostros de los días (véase imagen 10).

Imagen 9. Cruz maya con los 13 cuadros

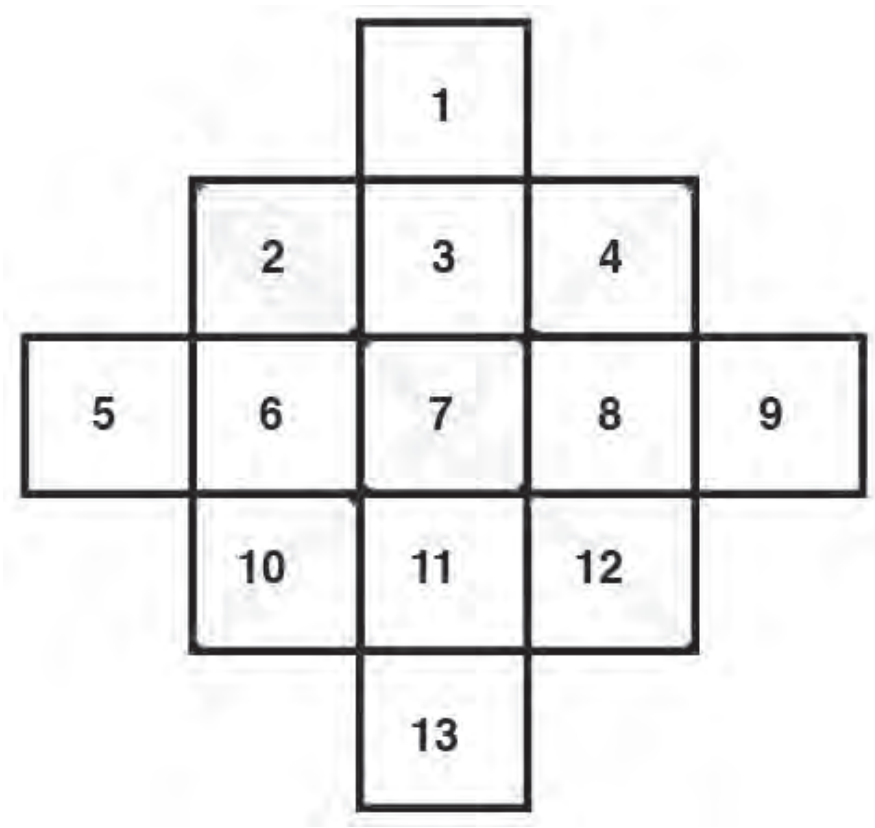

Imagen 10. Cruz maya con los 20 rostros

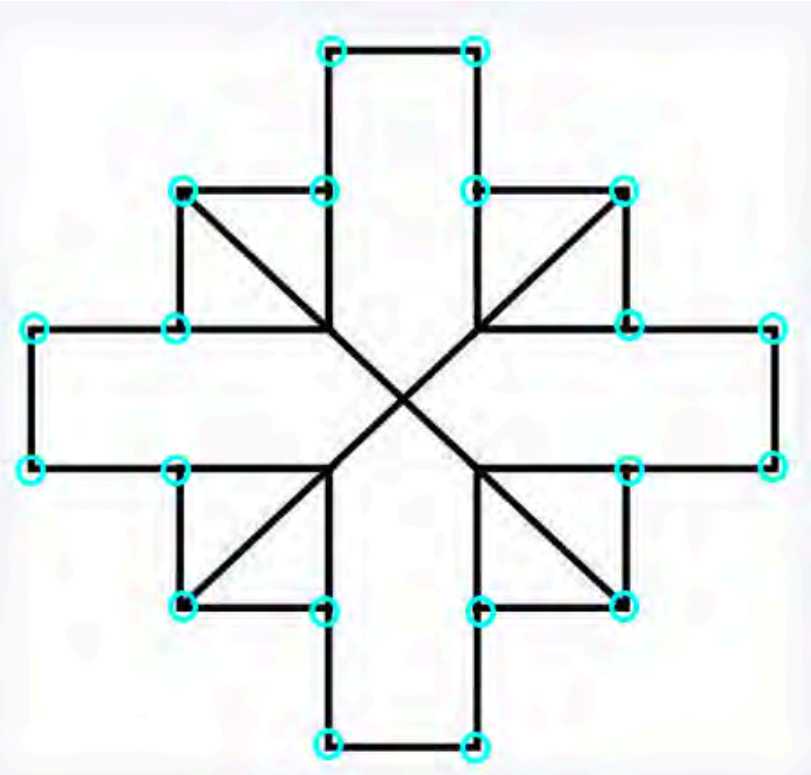


Imagen 11. Cruz maya convencional

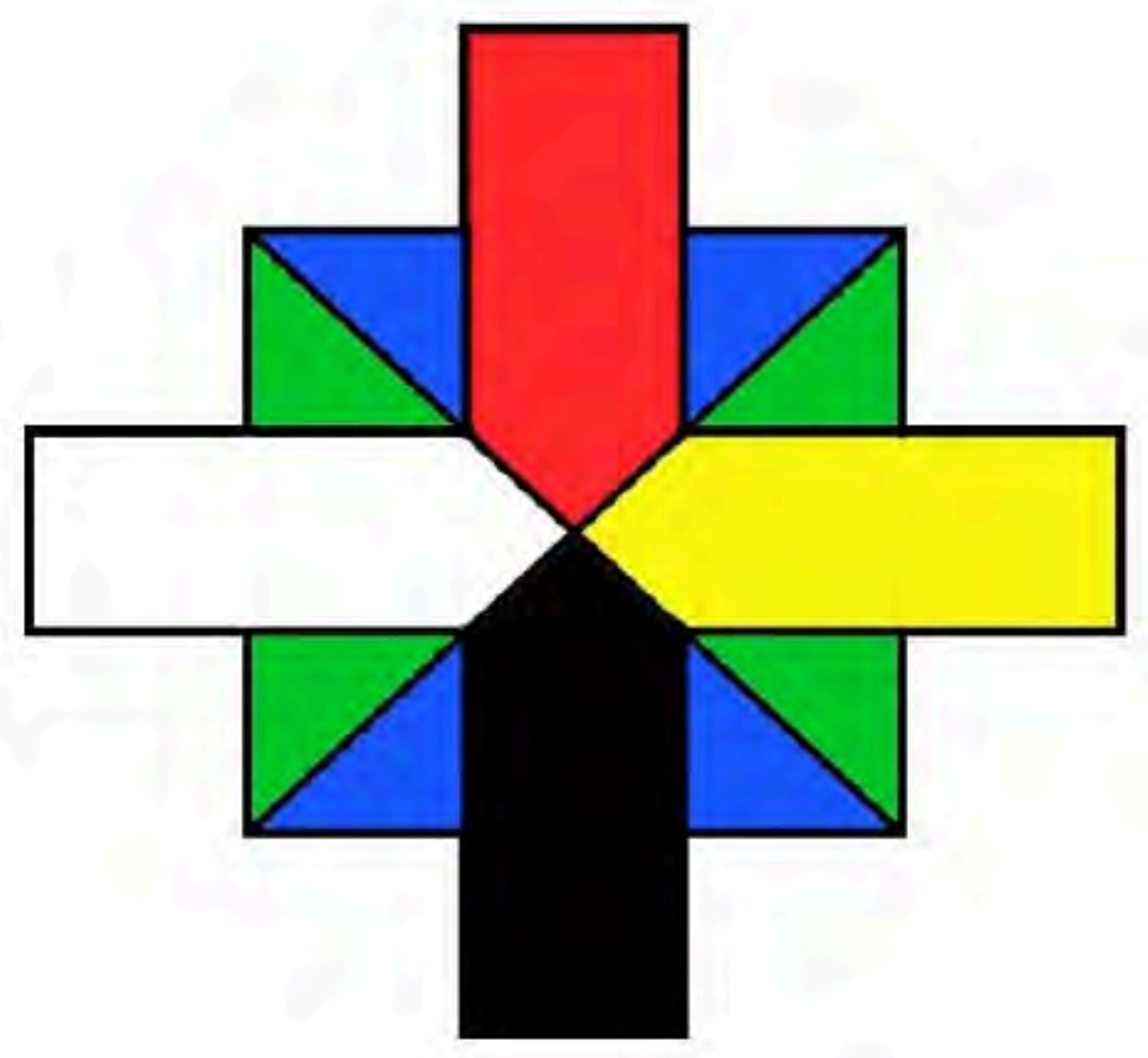

Cuadro 3. Rostro de días o Wäch q'ij de la cosmovisión Kaqchikel.

\begin{tabular}{|c|c|c|c|c|}
\hline Elemento & Agua & Aire & Tierra & Fuego \\
\hline Color de Maíz & Rojo & Blanco & Negro & Amarillo \\
\hline \multirow{5}{*}{ Wäch Q’ijj (Día) } & Imox & $1 q^{\prime}$ & Aq'ab'al & $K^{\prime}$ at \\
\hline & Kan & Kamey & Kej & Q'anil \\
\hline & Toj & $T z^{\prime} i^{\prime}$ & $B^{\prime} a t z^{\prime}$ & $E$ \\
\hline & $A j$ & I'x - B'alam & Tz'ikin & Ajmaq \\
\hline & No'j & Tijax & Kawoq & Ajpu' \\
\hline
\end{tabular}

Fuente: Elaboración propia. 
Los rostros de los días son los wäch q'ij que podemos tener de acuerdo con la fecha en que hayamos nacido. Aquí es importante aclarar que el uso de este calendario dista mucho de ser lo que algunas personas han querido interpretar de manera forzada, viendo en él una especie de horóscopo o medio de adivinación. Dada la amplitud del presente documento no habremos de ahondar en el sentido de cada una de las energías, pero sí conviene aclarar que la finalidad que ven en ellas las y los ajq'ija' es darnos medios para el autoconocimiento mediante el reconocimiento de nuestros aspectos positivos y negativos.

\section{f. LOS GUARDIANES Y ANCESTROS}

Los antepasados no son ajenos a nuestra vida, y los familiares difuntos forman parte de nuestra cotidianidad. Es por ese motivo que en los momentos ceremoniales se les da un espacio para que se comuniquen con quienes necesitan alguna orientación; incluso, dentro del conteo de los 20 días sagrados existe un día especial (Ajmaq) para que se manifiesten.

Asimismo, entre los espíritus también se encuentran los diferentes guardianes de los lugares sagrados (cerros, lagunas, altares, etc.); los personajes que han sido importantes para el pueblo Maya', tales como el Rijlaj Mam (Maximón), los ajpop, los ajq'ija', los líderes, dirigentes y también sus ancestros. Y son importantes en la CK los protectores de la naturaleza, los Saqik'oxol 'duendes blancos', los Käq k'oxol 'duendes rojos', los Saqb'ochol o Saqb'ichol, 15 y demás seres conocidos en las comunidades Maya', los cuales tienen una función específica. Lamentablemente, debido a la influencia del supuesto desarrollo «el ser humano ha invadido y destruido diferentes sitios sagrados, por lo que nos estamos quedando sin la protección de los seres que han mantenido el cuidado de esos espacios».

De hecho, es necesario recordar que todos los humanos tenemos un enorme árbol genealógico. En distintos momentos, así como tenemos nuestras altas y bajas energéticas en la vida, también nuestros antepasados las tuvieron; «dicen los ancianos y ancianas que en nuestra sangre existe información de tiempos remotos que muchas veces recordamos por medio de sueños, los cuales nos ayudan a corregir el rumbo de nuestra vida a través de las instrucciones de nuestros antepasados». Tales seres se cree que de igual forma «pueden pedir de nuestra ayuda para seguir con su proceso de trascendencia en los otros planos»,

${ }^{15}$ Es un espíritu guardián del bosque con forma de simio grande y peludo que habita en las cuevas. A este ser se le asocia con el Dios Chac en las culturas de origen Maya'. 
los cuales, como ya hemos dicho, se reconoce que están interconectados con el nuestro.

Imagen 12. Rijlaj Mam

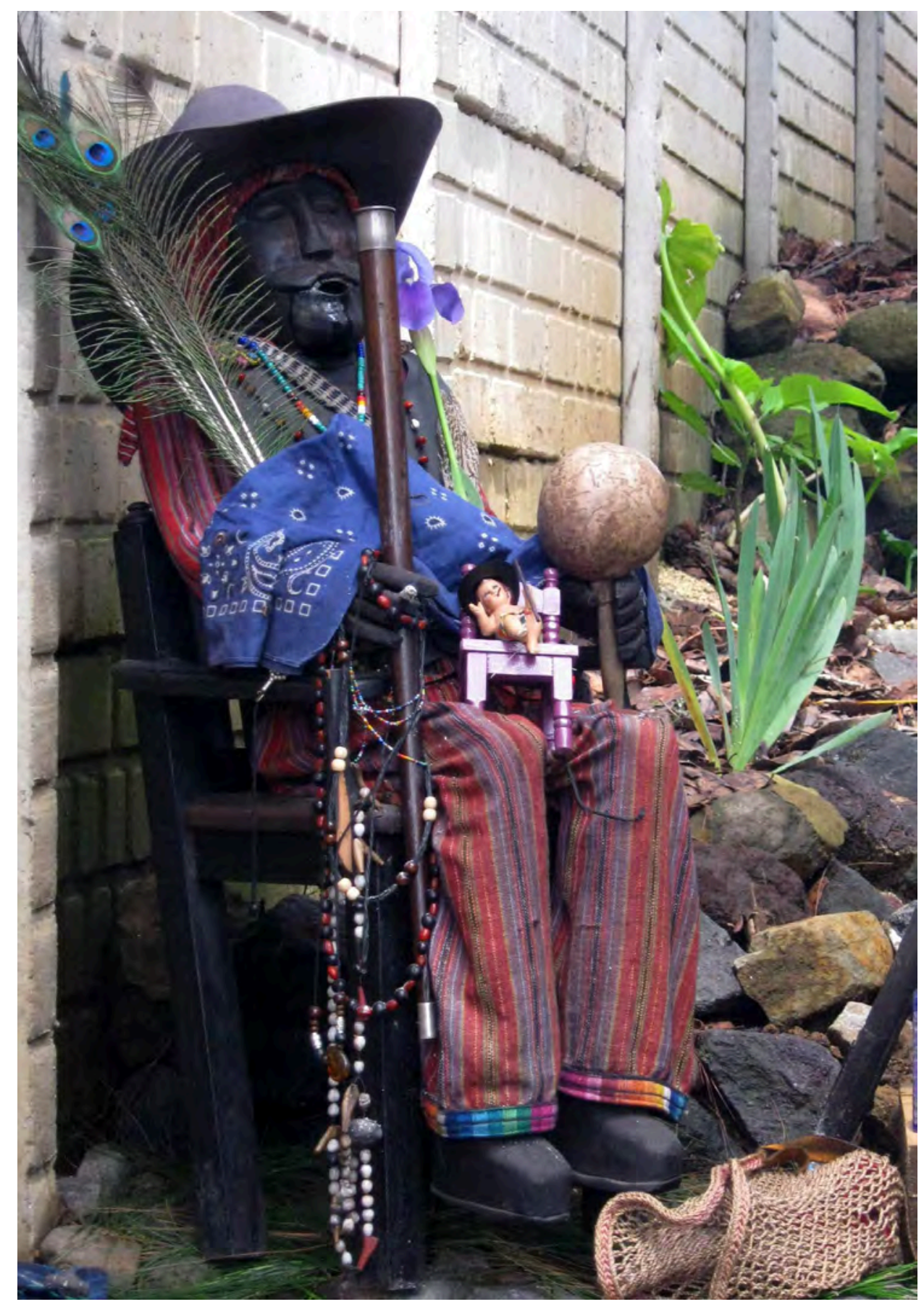




\section{g. JUNAMIL K'U'X Y EL EQUILIBRIO DE LA VIDA}

En el centro de los seres existe una esencia o espíritu, el corazón ${ }^{16}$ que para los pueblos Maya' es el núcleo del ser, el cual se encuentra en una constante búsqueda o anhelo de integrarse — sin perder sus rasgos particulares - con la esencia de todos los seres en la forma de una totalidad unificada. Una manera de hacerlo es a través del respeto que se demuestra al honrar las diferentes expresiones de la vida.

Así se describe en el Popol Vuh (Recinos 1960:108-109) cuando se relata cómo el Ser Supremo, Ilamado Tohil, pidió a los humanos que le dieran ofrendas y agradecieran de antemano todo lo que fueran a recibir —aunque esto pudiera no ser comprendido-, puesto que todo tiene su razón de ser. Fue así que se gestó la costumbre que hasta la fecha podemos palpar como parte de la espiritualidad de los pueblos Maya', de agradecer y ofrendar al ser Supremo y a los Guardianes, pidiendo para ello siempre la paz para todos los pueblos y para nuestra descendencia.

Profundizando en esto último, el concepto de paz es fundamental para los pueblos Maya', y a su vez está vinculada con el Nimab'äl K'u'x. Además de este último término, otro que también puede hacer referencia a la espiritualidad es uxlanib'äl k'u'x. La primera palabra significa «lugar de descanso o lugar de bienestar», es decir, tener la tranquilidad o la paz; la segunda se refiere a la esencia del ser. Por lo tanto, se habla de que la esencia, alma o espíritu de la persona está en una posición de tranquilidad y paz.

Cuando esa ofrenda es olvidada, la consecuencia es la pérdida de la energía básica, y esa es la causa principal de la enfermedad y la muerte, de esa forma el q'ij alaxïk o wäch q'ij, 17 la luz, la estrella o el destino que le fue otorgado al ser humano desde el día de su nacimiento, puede perder su Sol y su luz. Es decir, la «violación» de la armonía y el equilibrio de la persona se manifestará a través de su wäch q'ij y se reflejará en la forma de pesimismo, debilidad inmunológica, cáncer, diabetes y muchas otras enfermedades de suma gravedad.

Partiendo de estas ideas, los ajq'ija' consultados expresan que debemos reflexionar sobre cómo la espiritualidad ha ido quedando fuera de nuestras prioridades debido a que hemos depositado la fe en lo que nuestros sentidos nos

${ }^{16}$ Otra expresión en la cual se usa el término corazón es ki'nuk'ux, cuya traducción literal sería: «está dulce mi corazón», o bien, «estoy feliz».

${ }^{17}$ El q'ij alaxïk o wäch q'ij es lo que comúnmente se denomina nawal o nawali' en algunas áreas del territorio Maya' y por personas que aún no están inmersas en la práctica de la cosmovisión Maya' ni en el uso de algún idioma Maya'. 
indican que es «real». Utilizando como ejemplo el sentido y la práctica de la medicina, podemos ver que lamentablemente en la sociedad capitalista eso «real» y «cientificamente válido» son únicamente la cirugía, los medicamentos, las pastiIlas con vitaminas, etc. En aparente oposición están aquellos elementos que en la CK también son reales, como la música ancestral, los tambores, el uso de objetos curativos, la limpieza en puntos específicos del cuerpo, el uso de cristales, las plantas medicinales, etcétera. Por lo tanto, «hay que entender que estos últimos contienen energía», a menudo bastante imperceptible, pero es distinguida por los sentidos y, por consiguiente, determinan cambios físicos. Sin embargo, además del poder de los sentidos, los ajq'ija' reconocen que el poder del corazón, las palabras y el escuchar atentamente influyen demasiado en la vida de la persona enferma. Por lo tanto, esa misma actitud de enlace es como el/la ajq'ij se comunica con todas las manifestaciones de la naturaleza y el universo.

Para entenderlo en términos de la CK, un ajq'ij sugirió la analogía de que «así como la sangre corre por las venas y arterias, de ese modo la interconexión y la energía va y viene». Es decir, «es esa constante circulación o movimiento sincronizado la fuerza de la vida que existe en todas sus manifestaciones». Por lo tanto, como todos estamos formados de energía, cada uno puede influir en su entorno por estar conectados al «todo», independientemente de la distancia a la que estemos separados. Esta es otra manera de decir que todos estamos interrelacionados, enlazados unos a otros, viviendo en interdependencia.

Todo lo anterior lo podemos enmarcar en el problema de la pérdida de la armonía, y que en gran medida «es el resultado de la desconexión entre el ser humano y el cosmos», fruto de la conducta materialista y egoísta derivada del modelo de desarrollo, basado en el libre mercado y el consumismo. Al plantear lo anterior, reconocemos la complejidad del problema por ser una forma de vivir sumamente arraigada y que en apariencia no cambiará. Pero aquí es cuando toma forma y sentido la resistencia que ha caracterizado no solo al pueblo Kaqchikel, sino a la mayoría de los pueblos originarios.

Por lo tanto, hemos de replantear nuestro presente teniendo una mirada crítica y constructiva a fin de recuperar aquello positivo de nuestros orígenes. En concreto, la virtud de vivir en comunidad, en hermandad, y especialmente en complementariedad con todos los seres, en donde no haya explotados ni explotadores, donde no haya excluidos ni quienes excluyan, donde no haya marginados ni marginadores. 
Para los aja'ija' consultados, vivir en armonía significa «complementarnos y no competir»; «compartir y no aprovecharnos del vecino»; «vivir en armonía entre las personas y todos los otros seres, sean estos físicos-energéticos o energéticos, con quienes coexistimos». Esta posición sobre lo que significa vivir en colectividad «se contrapone a la búsqueda deshumanizadora de lujos absurdos, de opulencia y derroche que acarrea la explotación de la Madre Tierra».

\section{CONCLUSIONES}

Una primera reflexión que queremos hacer en el marco de la temática general de la presente publicación es que la armonía tanto para el pueblo Kaqchikel como para otros pueblos mesoamericanos se contrapone a la pretensión que ha habido desde algunos sectores académicos o políticos de ajustar el sentido de la armonía — también llamado buen vivir - a lo que para el mundo capitalista es el desarrollo. Consideramos que en el fondo ambas categorías son completamente opuestas. Eso, según el planteamiento de Santos (2009), es el riesgo permanente de la contrahegemonía, cuyos conceptos y categorías puedan ser tomados y deformados por la hegemonía con la intención de desviar la atención, privándolas así de su verdadero sentido.

Por nuestra parte, proponemos considerar la armonía como una buena forma de integrar los elementos del conocimiento cultural del puebo Kaqchikel. En primer lugar, es reflejo de la constelación, puesto que implica el equilibrio entre los diferentes ámbitos de la vida, tanto lo visible como lo invisible. En el caso del territorio, se describieron las relaciones con los seres materiales e inmateriales, que pueden ser conocidas y alimentadas por medio de calendarios y del Fuego Sagrado. En este, cada elemento tiene su significado y se integran con una lógica expresada a nivel lingüístico y matemático. Destaca cómo desde la visión Kaqchikel un territorio en armonía es una ampliación del sentido de la sustentabilidad, puesto que no se reduce a una cuestión económica o material, sino que implica una actitud de respeto y búsqueda del bien común entre diferentes seres en el momento presente y futuro.

Al hablar de respeto como un elemento sustantivo de la armonía queremos recalcar que para la CK esta no es el resultado de aplicar una receta ni una fórmula, es el fruto de una forma particular de vivir que debe partir del autoconocimiento y de la comprensión del sentido de «todas nuestras relaciones». Esto se logra mediante el estudio de nuestros wäch q'ij. Al hacerlo, hay que reconocer nuestras 
similitudes e incluso nuestro origen común, pero diferenciar eso de la homogeneización. ${ }^{18}$ Es decir, podremos tener un pasado u origen común, un sueño o anhelo similar y aun así mantener nuestras formas particulares de construirlo. Cuando eso se pasa por alto y se pretende lograr la homogeneidad, entonces es cuando emerge el sentido de resistencia.

En el ámbito espiritual, las ceremonias de Fuego Sagrado son un ejemplo claro de la manera en que se busca evitar subsumirse a una lógica impuesta y deshumanizante. Cabe señalar que la resistencia no implica negarse al cambio. De hecho la renovación lleva a poder cambiar, pero como fruto de una decisión libre y consciente. Al respecto, los ajq'ija' reconocen que la práctica no es la misma en su forma, y aunque hayan cambiado algunas de las ofrendas, la intencionalidad es la que mantiene su esencia. Asimismo, si bien aún existe cierta incredulidad por parte de un sector importante de los pueblos Maya' para compartir la tradición, quienes participaron en los espacios de discusión y consulta concordaron en que se debe abrir para que la humanidad se enriquezca con la tradición Maya'.

En cuanto a la dialéctica panteísta, se reconoce que el sentido de colectividad e integración con el cosmos puede ser un aporte importante de parte de los pueblos originarios, sobre todo en esta época en que el consumismo y la enajenación han desconectado al ser humano de su sentido de vida. En nuestra opinión, el acercamiento a experiencias como el Fuego Sagrado, en las cuales se pueda practicar la dialéctica panteísta, puede ser de gran valor para las sociedades actuales. Resulta apremiante superar el uso mercantilista de la religión y la concepción panmonetaria de la Naturaleza, a fin de revitalizar nuestras prácticas con el respeto por todo lo que esta implica. De hecho, para la CK nadie ni nada está solo, uno es complemento del otro. Por eso existe la paridad, la complementariedad, la dualidad de las cosas. El ser humano es un microcosmos dentro del macrocosmos, es pequeño y grande a la vez. Es energía y es materia.

\footnotetext{
${ }^{18}$ Sobre este origen común, Panikkar (1999:37) obtiene unas conclusiones importantes a partir de revisar diferentes libros sagrados, y es que «Todo tiene el mismo Origen, todo está relacionado, el universo entero es una familia, un macro-organismo; lazos de sangre, por decirlo así, animan todo lo que es. Somos de la misma raza. Somos los miembros desmembrados de ese Cuerpo. Nuestra tarea (y nuestro privilegio) es rememorar el cuerpo desmembrado, hacerlo un todo, es decir, sanar a integrar todos los disjecta membra de la realidad, esparcidos como están a través del tiempo y el espacio. La energía para esta salvación puede proceder de múltiples direcciones, pero tiene una única fuente».
} 
Al hacer estos planteamientos estamos conscientes de la tendencia de la denominada posmodernidad a evitar los metarrelatos religiosos, sobre todo porque se suele identificar a la religión con la coerción o con la construcción de una especie de dosel tranquilizador, con el cual evadamos nuestra responsabilidad en nuestro proceso vital. Aquí queremos mostrar que hay un papel para la espiritualidad que resulta cada vez más evidente e importante, la esperanza como fuerza motora. Ésta puede ser un vehículo para la autotransformación mediante el apoyo que podamos tener en los principios, preceptos y prácticas que nos orienten en cómo cambiar y estar más en armonía.

Esa armonía no es algo fortuito, y tampoco se puede comprar ni ser el resultado de una imposición. Al enmarcar el presente análisis en la dialéctica negativa queremos reconocer que el dolor implícito en el camino de la deconstrucción y reconstrucción de las personas, según lo expresado por los ajq'ija' "es más sencillo si se aceptan tanto la luz como la oscuridad». Asimismo, no es una cuestión de sometimiento sobre uno mismo o sobre las demás personas, sino de toma de conciencia del sentido de la libertad.

\section{FUENTES DE CONSULTA}

Adorno, Theodore, 2007, Dialéctica negativa, Madrid, Taurus Humanidades.

Bloch, Ernst, 1980, El principio esperanza, Madrid, Aguilar.

Brinton, Daniel, 2012, The Maya chronicles, USA, HardPress.

Casas, Bartolomé de las, 2004, Los indios de México y Nueva España, México, Porrúa.

Clavijero, Francisco Javier, 1979, Historia Antigua de México, México, Porrúa.

Cojtí-Cuxil, Demetrio, 2006, Runa'Oj Ri Maya' Amaq': Configuración del Pensamiento Político del pueblo Maya', Guatemala, Cholsamaj.

Cortés y Larraz, Pedro, 1958, Descripción geográfico-moral de la diocesis de Goathemala, 1768-1770, Guatemala, Sociedad de Geografía e Historia de Guatemala.

Díaz del Castillo, Bernal, 1980, Historia de la Conquista de Nueva España, México, Porrúa.

Farris, Nancy, 1984, Maya Society Under Colonial Rule: The Collective Enterprise of Survival, Princeton, Princenton University Press.

Fuentes y Guzmán, Francisco, 1932, Recordación Florida. Discurso historial y demostración material, militar y política del Reyno de Goathemala, Guatemala, Sociedad de Geografía e Historia de Guatemala.

Friedel, David, Linda Schele y Joy Parker, 1999, El Cosmos Maya, México, Fondo de Cultura Económica.

García de León, Antonio, 1985, Resistencia y Utopía, Memorial de agravios y crónicas de revueltas y profecías acaecidas en la provincia de Chiapas durante los últimos quinientos años de su historia, t. 1, México, Editorial Era. 
Guillemín, Jorge, 1980, Iximché: capital del antiguo reino cakchiquel, Guatemala, Instituto de Antropología e Historia de Guatemala.

Kuper, Adam, 2001, Cultura: la versión de los antropólogos, Barcelona, Paidós.

Landa, Diego de, 1986, Relación de las cosas de Yucatán, México, Porrúa.

Le Bot, Yvon, 2013, La gran revuelta indígena, México, Océano.

Limón, Fernando, 2010, Conocimiento cultural y existencia entre los chuj, México, Comisión Nacional para el Desarrollo de los Pueblos Indígenas.

Martínez, Severo, 1998, La patria del criollo: Ensayo de interpretación de la realidad colonial guatemalteca, México, Fondo de Cultura Económica.

Morgan, Lewis, 1944, Ancient Society, U.S.A., The University of Arizona Press.

Olivé, León, 2004, Interculturalismo y Justicia Social, México, Universidad Autónoma de México.

Panikkar, Raimon, 1999, La Intuición Cosmoteándrica: las tres dimensiones de la realidad, Madrid, Trotta. , 2007, Mito, Fe y Hermenéutica, Barcelona, Herder.

Paz-Cárcamo, Guillermo, 2004, Chuwa Nima Abäj, Guatemala, Cholsamaj. 2006, La mascara de Tekum, Guatemala, Cholsamaj.

Polo Sifontes, Francis, 1977, Los cakchiqueles en la conquista de Guatemala, Guatemala, Instituto de Antropología e Historia de Guatemala.

Recinos, Adrián (trad.), 1957, "Título de la casa Ixquín-Nehaib, señora del territorio de Otzoyá» en Crónicas Indígenas de Guatemala, Adrián Recinos (ed.), Guatemala, Editorial Universitaria.

, 1960, Popol Vuh, México, FCE.

, 2013, Memorial de Sololá, Guatemala, Fondo de Cultura Económica.

Rostow, Walt W., 1993, Las etapas del crecimiento económico. Un manifiesto no comunista, Madrid, Ministerio de Trabajo y Seguridad Social.

Rupflin-Alvarado, Walburga, 1999, El Tzolkin es más que un calendario, Guatemala, Fundación Centro de Documentación e Investigación Maya.

Sahagún, Bernardino, 2006, Historia General de las cosas de Nueva España, México, Porrúa.

San Martín, Javier, 1999, Teoría de la Cultura, España, Síntesis.

Santos, Boaventura de Sousa, 2009, Una epistemología del sur, México, Siglo XXI.

Thompson, Eric, 1966, The rise and wall of Maya civilization, Oklahoma, University of Oklahoma. 1979, Historia y Religión de los Mayas, México, Siglo XXI.

Villoro, Luis, 1987, Los Grandes momentos del indigenismo en México, México, El Colegio Nacional - Secretaría de Educación Pública.

Worsley, Peter, 1974, Introducing sociology, UK, Penguin.

Ximénez, Francisco, 1985, Primera parte del Tesoro de las Lenguas Cakchiquel, Quiché y Zutuhil, en que las dichas lenguas se traducen a la nuestra, española, Guatemala, Academia de Geografía a Historia de Guatemala.

Fecha de recepción: 21 de mayo de 2014 Fecha de aceptación: 9 de marzo de 2015 